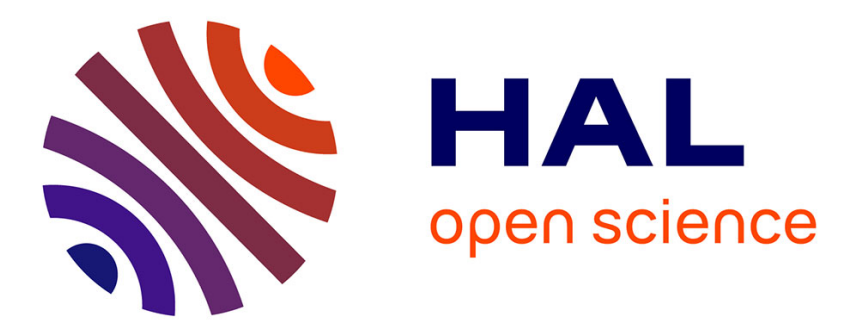

\title{
L'enregistrement tardiglaciaire de Dourges (Nord de la France, bassin de la Deûle) : évolution d'une zone lacustre et gisements archéologiques associés
} Laurent Deschodt, Eric Teheux, J. Lantoine, Patrick Auguste, Nicole Limondin-Lozouet

\section{To cite this version:}

Laurent Deschodt, Eric Teheux, J. Lantoine, Patrick Auguste, Nicole Limondin-Lozouet. L'enregistrement tardiglaciaire de Dourges (Nord de la France, bassin de la Deûle) : évolution d'une zone lacustre et gisements archéologiques associés. Quaternaire, 2005, vol. 16/3, pp.229 - 252. 10.4000/quaternaire.457 . hal-01490639

\section{HAL Id: hal-01490639 \\ https://hal-inrap.archives-ouvertes.fr/hal-01490639}

Submitted on 3 Apr 2017

HAL is a multi-disciplinary open access archive for the deposit and dissemination of scientific research documents, whether they are published or not. The documents may come from teaching and research institutions in France or abroad, or from public or private research centers.
L'archive ouverte pluridisciplinaire HAL, est destinée au dépôt et à la diffusion de documents scientifiques de niveau recherche, publiés ou non, émanant des établissements d'enseignement et de recherche français ou étrangers, des laboratoires publics ou privés. 


\title{
L'ENREGISTREMENT TARDIGLACIAIRE DE DOURGES (NORD DE LA FRANCE, BASSIN DE LA DEÛLE) : ÉVOLUTION D'UNE ZONE LACUSTRE ET GISEMENTS ARCHÉOLOGIQUES ASSOCIÉS
}

\author{
L. DESCHODT ${ }^{1}$, E. TEHEUX ${ }^{1}$, J. LANTOINE ${ }^{1}$, \\ P. AUGUSTE ${ }^{2}$ et N. LIMONDIN-LOZOUET ${ }^{3}$
}

\begin{abstract}
RÉSUMÉ
Une dépression dans le fond de la vallée de la Deûle, au pied du versant crayeux de la Gohelle (bassin minier de Lens), a permis la mise en place et la conservation de sédiments tardiglaciaires lacustres et palustres avec des sites paléontologiques et archéologiques associés. La nature des dépôts est commandée par les variations d'humidité. Un épisode lacustre est daté du Bølling. Il est caractérisé par le développement d'une biocénose aquatique (poissons et mollusques). Un fragment de harpon magdalénien et les restes d'un aurochs de grande taille ont été trouvés dans le tuf lacustre. Le Dryas moyen se distingue par un assèchement et un hiatus stratigraphique. Après une nouvelle période d'hydrologie plus marquée (récurrence de crues de courte durée), la zone redevient marécageuse à l'Allerød. Elle est fréquentée par des chasseurs Federmesser ainsi qu'en témoigne une halte de chasse qui a livré des éléments fugaces mais caractéristiques : sagaie, pointe en os barbelée, pointe de flèche. La fin de l'Allerød se caractérise par un retour à des conditions sèches et la formation d'un sol humifère. Le refroidissement du Dryas récent engendre une déstabilisation du versant et le début du comblement de la dépression par des colluvions limoneuses. Leur base a livré un crâne d'élan.
\end{abstract}

Mots-clés : Tardiglaciaire, vallée de la Deûle, France, lac, tuf, Magdanénien, Federmesser.

\section{ABSTRACT}

THE DOURGES LATE GLACIAL RECORD (NORTH OF FRANCE, DEÛLE RIVER BASIN): LACUSTRINE AREA EVOLUTION AND CONNECTED ARCHAEOLOGICAL SITES

A dip in the Deûle valley, bottom the chalky slope of the Gohelle country (Lens mining basin), has yielded Late Glacial deposits with palaeontological remains and archaeological artifacts. The nature of the deposits appears linked to humidity variations. A lacustrine episode dated from the Bølling is characterized by the development of an aquatic biocoenosis (fish and mollusks). A fragment of a Magdalenian harpoon and the remains of a large wild ox were discovered in the lacustrine tufa. The Older Dryas corresponds to dry conditions and a stratigraphic hiatus. After a new increase in hydrological conditions (short floodings), the area turns marshy again during the Allerød. FEDERMESSER hunters are represented by assegai, barbed bone points and arrow points. The end of the Allerød corresponds to a return to dry conditions and the formation of humic soil. During the Younger Dryas the cooling provokes slope erosion and the filling up of the hollow by silt colluvium. An elk skull was discovered at the base of this last deposit.

Key-words: Late Glacial, Deûle valley, France, lake, calcareous tufa, Magdalenian, Federmesser.

\section{1 - LE CONTEXTE GÉOGRAPHIQUE ET L'HISTORIQUE DES RECHERCHES}

La découverte et l'étude du gisement de Dourges représentent une partie des opérations d'archéologie préventive préalables aux aménagements de la plateforme multimodale de Dourges. Cette zone logistique de transport est aménagée dans une région basse au relief peu marqué entre le glacis crayeux de la Gohelle qui s'élève lentement vers les plateaux artésiens et les collines développées sur les sables et argiles tertiaires du Pévèle (fig. 1). Bien que fortement urbanisée et industrialisée (bassin minier de Lens), la couverture sédimentaire de la zone de Dourges était méconnue dans son détail. Tout au plus savions-nous qu'une couverture loessique masquait le passage de la craie secondaire aux argiles et sables tertiaires de la Pévèle. La carte géologique 1/50000 du BRGM (Desoignies et

\footnotetext{
${ }^{1}$ INRAP Nord-Picardie, 518 rue St-Fuscien, 80000 Amiens, 1deschodt@nordnet.fr,

${ }^{2}$ Laboratoire Préhistoire et Quaternaire, UMR 8018 CNRS, Université des Sciences et Technologies de Lille 1, Bâtiment de Géographie, 59655

Villeneuve d'Ascq Cedex, Patrick.Auguste@univ-lille1.fr

${ }^{3}$ Laboratoire de Géographie Physique, UMR 8591 CNRS, Laboratoire de Géographie Physique, 1 Place A. Briand, 92195 Meudon cedex,

limondin@cnrs-bellevue.fr
} 

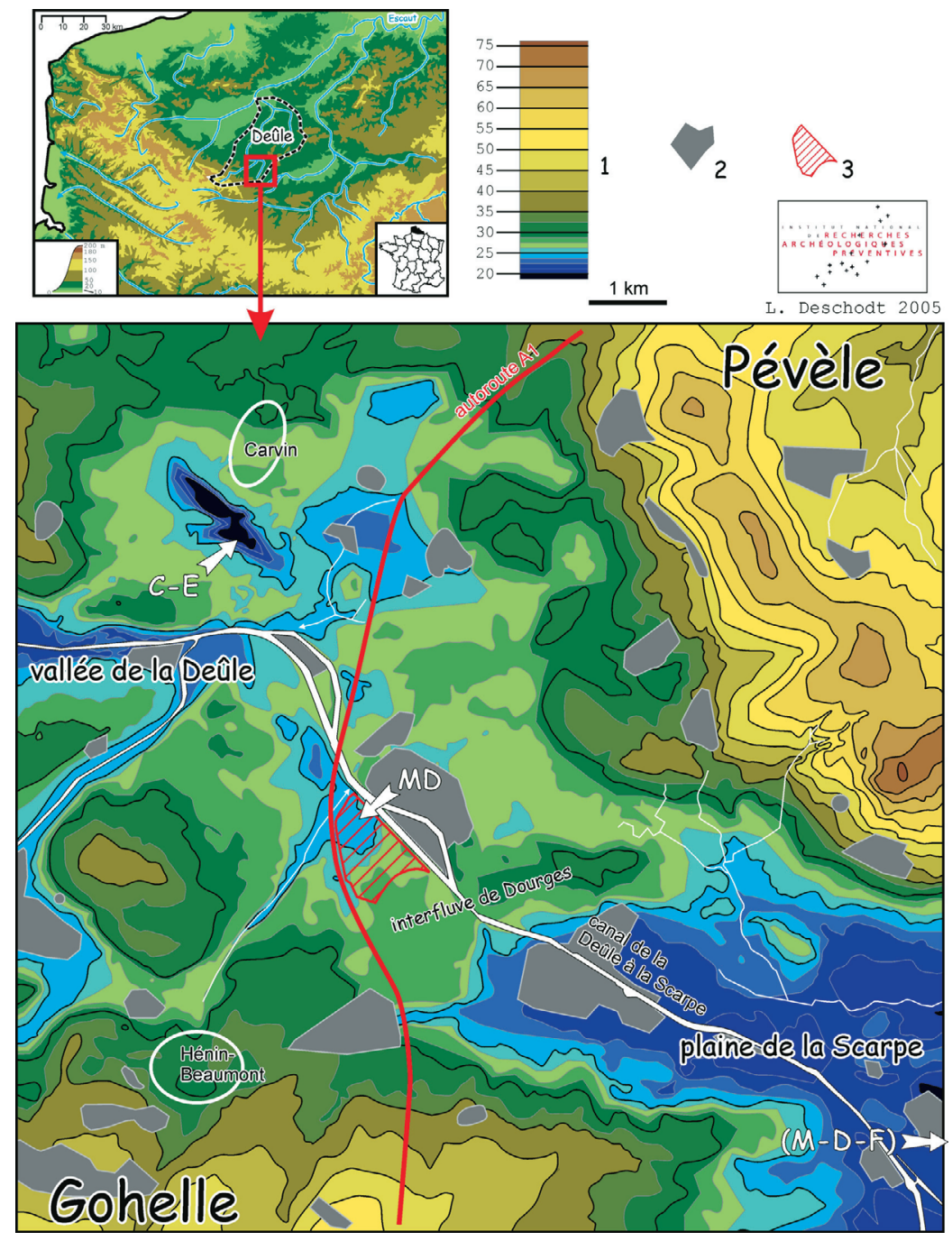

Fig. 1 : Topographie de la région de Dourges d'après les cartes IGN 1/25000 n 2505 Ouest et Est.

1) altitude en mètres NGF-Lallemand (NB : dans la région lilloise, système de référence IGN69 = NGF-Lallemand + environ 0,6 m) ; 2) topographie profondément bouleversée par l'activité humaine (terril, carrière, zone industrielle...) ; 3) localisation du marais de Dourges et du bas de versant limitrophe (fig. 2) ; C-E) dépression de Carvin-Epinoy ; MD) dépression du «Marais de Dourges », cet article ; (M-D-F) «Mer-de-Flines », plan d'eau environ 6 km à l'est de la zone cartographiée, sur la commune de Flines-lez-Raches.

Fig. 1: Dourges area topography according to IGN 1/25000 maps $n^{\circ} 2505 O$ and $E$.

1) elevation, NGF-Lallemand survey (NB: in the Lille area, IGN69 survey = NGF-Lallemand + about $0.6 \mathrm{~m}$ ); 2) topography highly disturbed by human activity (spoil heap, quarry, industrial area...); 3) location of the Dourges marsh and adjacent slope bottom (fig. 2); C-E) Carvin-Epinoy dip $M D)$ «Marais de Dourges », this paper; $(M-D-F)$ "Mer-de-Flines », natural pond about $6 \mathrm{~km}$ east from mapped area (Flines-lez-Raches district).
Sangnier, 1968) indique par ailleurs une vaste zone d'alluvions récentes grossièrement sous la courbe de niveau 25 mètres N.G.F-Lallemand, délimitant la prolongation la plus orientale des zones humides du fond de vallée de la Deûle. Les sondages géotechniques préparatoires aux travaux, effectués sur l'ancien carreau de mine de la fosse $\mathrm{n}^{\circ} 10$ (à Oignies) ont rencontré la craie entre 7 et 13 mètres de profondeur (sondages du Laboratoire régional des Ponts et Chaussées de Lille).

Afin de mieux évaluer le potentiel archéologique et les moyens nécessaires aux sondages archéologiques, le Service Régional de l'Archéologie a préconisé la réalisation d'une première investigation dans la zone la plus basse dite «Marais de Dourges» (fig. 2) (sur la commune d'Hénin-Beaumont, en limite du territoire de Dourges). Une première reconnaissance à la pelle mécanique, selon une trame relativement lâche, a été réalisée dans le but d'appréhender la stratigraphie, le potentiel archéologique et de préparer les sondages. Des formations tuffacées et tourbeuses postérieures au dépôt loessique ont été observées (Deschodt et Blancquaert, 2000). Une méthode de sondages adaptée a ainsi pu être mise en place. Elle a abouti à la découverte de sites archéologiques et paléontologiques (Teheux et Deschodt, 2000).

\section{2 - LES DONNÉES LITHOSTRATIGRAPHIQUES}

\section{1 - DESCRIPTION}

Au maximum de dilatation des formations sédimentaires, nous observons, de bas en haut (figs 3 et 6, photo 2) :

1 - Limon loessique, faciès de fond de vallée à graviers de craie épars. Le limon est gleyifié (verdâtre très claire) dans les zones basses. Il passe à un pseudogley en position haute dans le marais (vert avec marbrures rouilles) et devient jaunâtre sur le versant. La granulométrie correspond à un loess typique (fig. 9). Toutefois, l'unité peut comporter des lits de sables glauconieux et parfois des épandages de graviers de craie, plus rarement des rognons de silex (fig. 5). La topographie de son toit est particulièrement irrégulière (photos 1 et 4 ).

2 - Horizon tourbeux inférieur (niveau repère « HTI »). Uniquement présent sur une faible aire, dans la zone la plus basse (fig. 4). Il s'accompagne de malacofaunes volumineuses et de graviers de craie. Les limites de l'unité sont souvent diffuses et déformées par des figures de charge. 


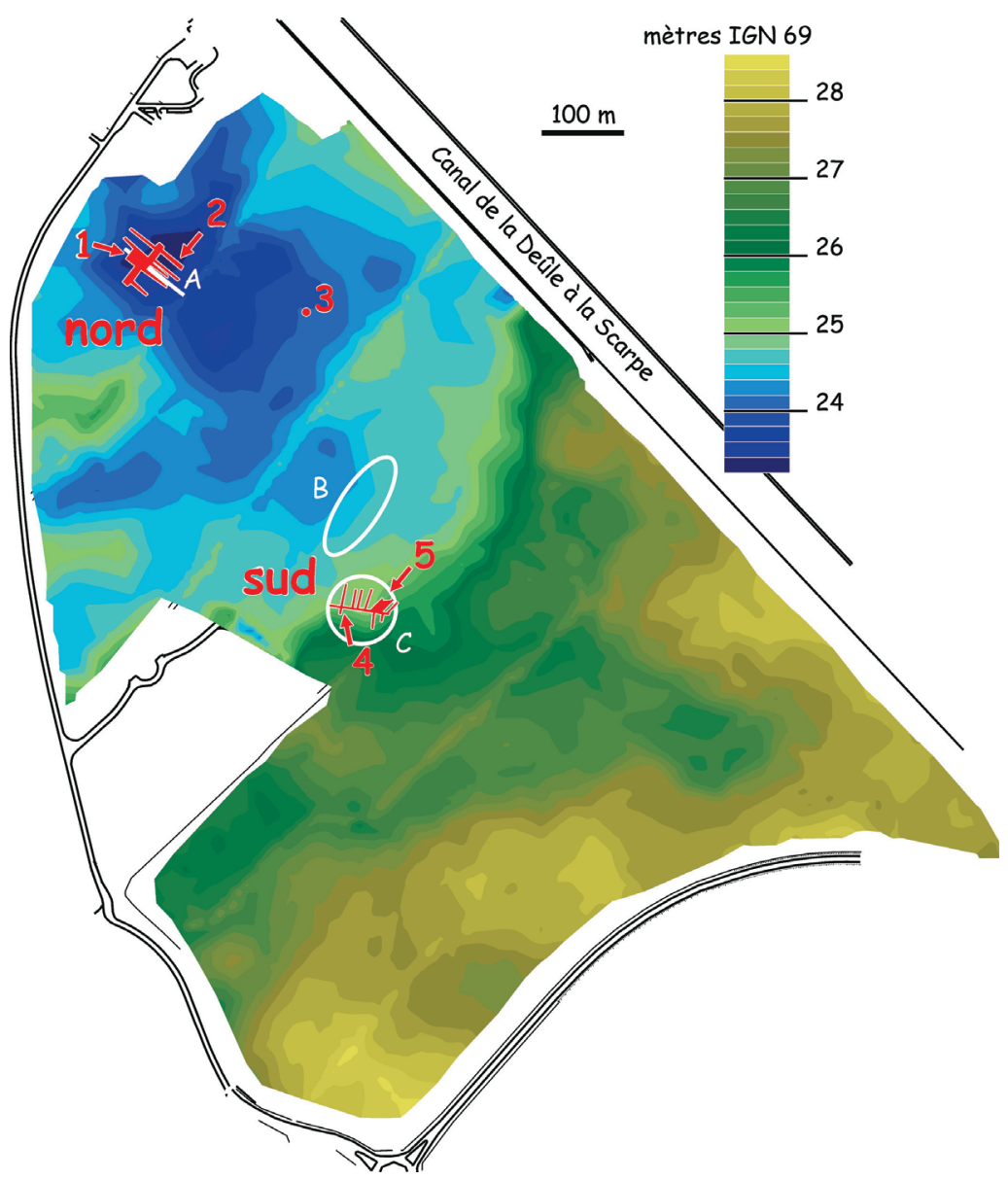

Fig. 2 : Microtopographie du « Marais de Dourges » et de sa jonction avec le versant, localisation des zones fouillées en mètres IGN 69, équidistance de $0,2 \mathrm{~m}$; d'après un document fourni par «Delta 3 » et complété par des levés INRAP.

1) fouille manuelle en zone nord (site Federmesser et harpon madgalénien) ; 2) maximum de dilatation des alluvions et prélèvements ; 3) crâne d'élan découvert en sondage ; 4) crâne d'aurochs découvert en sondage ; 5) fouille manuelle en zone sud ; $\mathrm{ABC}$ ) localisation des éléments de la synthèse stratigraphique (fig. 3 ).

Fig. 2: Dourges marsh and slope microtopography, location of excavated aeras IGN 69 survey, $0.2 \mathrm{~m}$ contour lines; according to an INRAP supplemented "Delta 3" document.

1) north area manual excavation (Federmesser site and Magdalenian harpoon); 2) area of greatest thickness of alluvium and samples location; 3) Elk skull found in a test pit; 4) Wild Ox skull found in a test pit; 5) manual excavation in the south area; $A B C)$ location of the stratigraphic synthesis components (fig. 3)

3 - Limon tuffacé inférieur, très clair et calcaire, gris verdâtre à petites taches rouilles diffuses. En l'absence de (2), l'unité se distingue mal de (1), si ce n'est par la concentration de petits graviers de craie à leur limite. Quelques lits très calcaires sont perçus au maximum de dilatation.

4 - Tuf calcaire, formé majoritairement de sédiment calcaire précipité (plus de $70 \%$ du poids sec, cf. fig. 9), extrêmement clair (blanc légèrement jaunâtre), à abondantes et volumineuses malacofaunes. Au maximum de la dilatation, quelques lits s'enrichissent brutalement d'une composante organique, formant alors un sédiment brun gris, peu compact, déformé par des figures de charges. L'unité se poursuit sur une très grande surface, jusque dans les parties hautes du marais sous la forme d'un mince niveau (ordre centimétrique) (fig. 4).

5 - Horizon tourbeux moyen (niveau repère « HTM »), horizon limoneux brun tourbeux qui se confond latéralement avec l'horizon tourbeux supérieur. L'unité ne prend un faciès franchement tourbeux que sur une longueur de quelques mètres au maximum de la dilatation.

6 - Limon tuffacé moyen, limon brun gris clair, à petites taches rouilles diffuses, calcaire (taux irrégulièrement dans l'unité, plus de $20 \%$ du poids sec en partie supérieure, cf. fig. 9), avec des malacofaunes, quelques lamines discrètes. Le faciès est très proche de celui de l'unité 7 dont il est séparé par un lit de limon non cohérent avec des restes de poissons.
7 - Limon tuffacé supérieur, limon brun gris clair, à petites taches rouilles diffuses, très calcaire (pic à près de $40 \%$ du poids sec, cf. fig. 9), avec malacofaunes et quelques lamines discrètes. Le faciès est identique à l'unité 6 dont il est séparé par un lit de limon non cohérent avec des restes de poissons

8 - Horizon tourbeux supérieur brun, (niveau repère «HTSb»). Son faciès est similaire à l'unité 5 (HTM) avec lequel il se confond latéralement. Au maximum d'épaisseur, le sommet de l'unité présente un liséré sombre similaire à 9 . Le gisement archéologique Federmesser se développe au sommet de cette unité, en bordure de la dépression (fig. 3)

9 - Horizon tourbeux supérieur noir, horizon repère «HTSn », mince horizon de sol très sombre $(2$ à $3 \mathrm{~cm}$ ) avec traces de radicelles en limites inférieures, non calcaire et extrêmement régulier (épouse la topographie sous-jacente). L'unité surmonte directement l'horizon tourbeux supérieur (8) mais son extension est plus grande : elle se poursuit jusque dans les zones les plus élevées sans changer de faciès.

10 - Limon oxydé, limon jaune orangé vif à rouille, non calcaire, d'épaisseur variable (quelques centimètres à quelques décimètres d'épaisseur), l'unité n'existe que sur des secteurs en pentes (mais non systématiquement) et sur une partie du talweg de la zone sud. Il présente souvent un front convexe vers le bas de la pente. L'unité 10 recouvre systématiquement l'unité 9 (HTSn). 


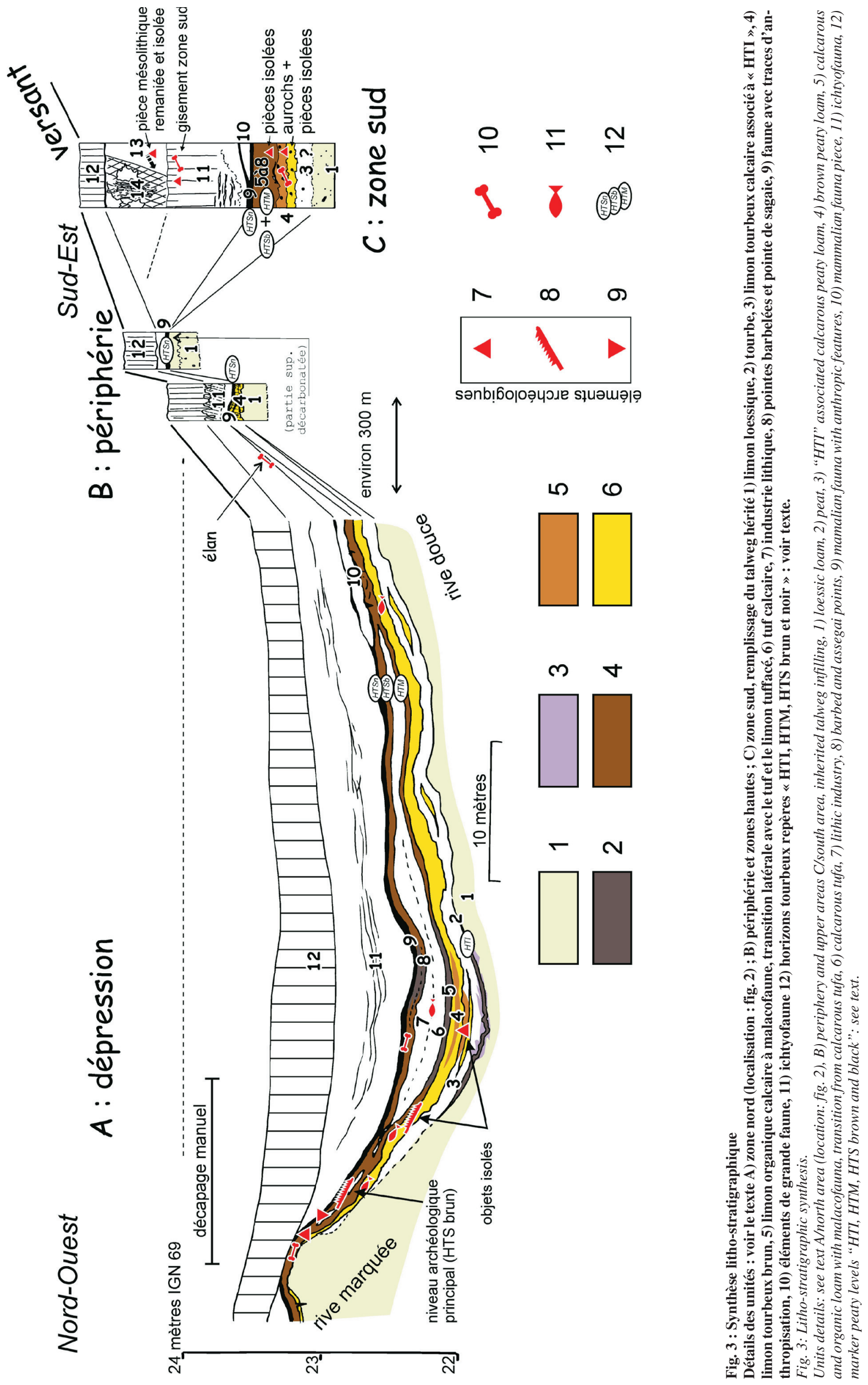


Fréquemment, l'unité 10 est surmontée d'un liséré sombre similaire et en continuité avec 9 .

11 - Limon gris, développé sur une très vaste zone. Il contribue en grande partie au comblement de la cuvette. L'unité 11 est hétérogène. Le front de décarbonatation la traverse irrégulièrement. Fréquemment, des faisceaux de lits diffus de sédiments plus clairs ont été observés. Dans la majorité des cas, l'unité 11 recouvre les unités 9 et 10 sans érosion perceptible, à l'exception de quelques sondages où des écoulements provenant du versant démantèlent l'unité 9 et les dépôts tuffacés sous-jacents (photo 5 et figure 5).

\section{2 - Labours}

13 - Déstabilisation de l'encaissant loessique (zone sud uniquement). L'unité 11 est localement recouverte par le remaniement de la rive loessique. Elle contient une pièce mésolithique isolée (microburin).

14 - Tourbe gallo-romaine (zone sud uniquement). Une formation de tourbe calcaire riche en faune conclut le comblement de la zone sud (photo 4).

\section{2 - LES VARIATIONS LATÉRALES ET LE SYSTÈME MORPHO-SÉDIMENTAIRE}

Les trois niveaux organiques (HTI, HTM, HTSb/n) constituent des repères fiables utilisés en sondages à la pelle mécanique. Leur répartition est régulière mais non uniforme : l'unité 2 (HTI) n'est présente que vers $22 \mathrm{~m}$ d'altitude sur une aire restreinte au nord du marais (fig. 4) qui correspond au maximum de la dilatation de la séquence (fig. 5 et photo 2). En s'éloignant du centre de la dépression, la tourbe médiane 5 (HTM), se confond très vite, en remontant, avec le niveau 8 de faciès identique (HTSb) (fig. 3 et photo 3 ). Le tuf (4) et l'horizon supérieur noir (9, HTSn) (fig. 4) ont une très grande extension et se retrouvent en périphérie de la zone alluviale à des altitudes élevées de l'ordre de 23,5 mètres. L'unité 9 a une épaisseur constante qui épouse la topographie sous-jacente, l'ensemble des unités contribue à combler et à masquer une microtopographie particulièrement irrégulière au sommet du limon loessique.

Des figures de charges affectent les unités inférieures au droit des zones où les unités sont les plus épaisses. Il

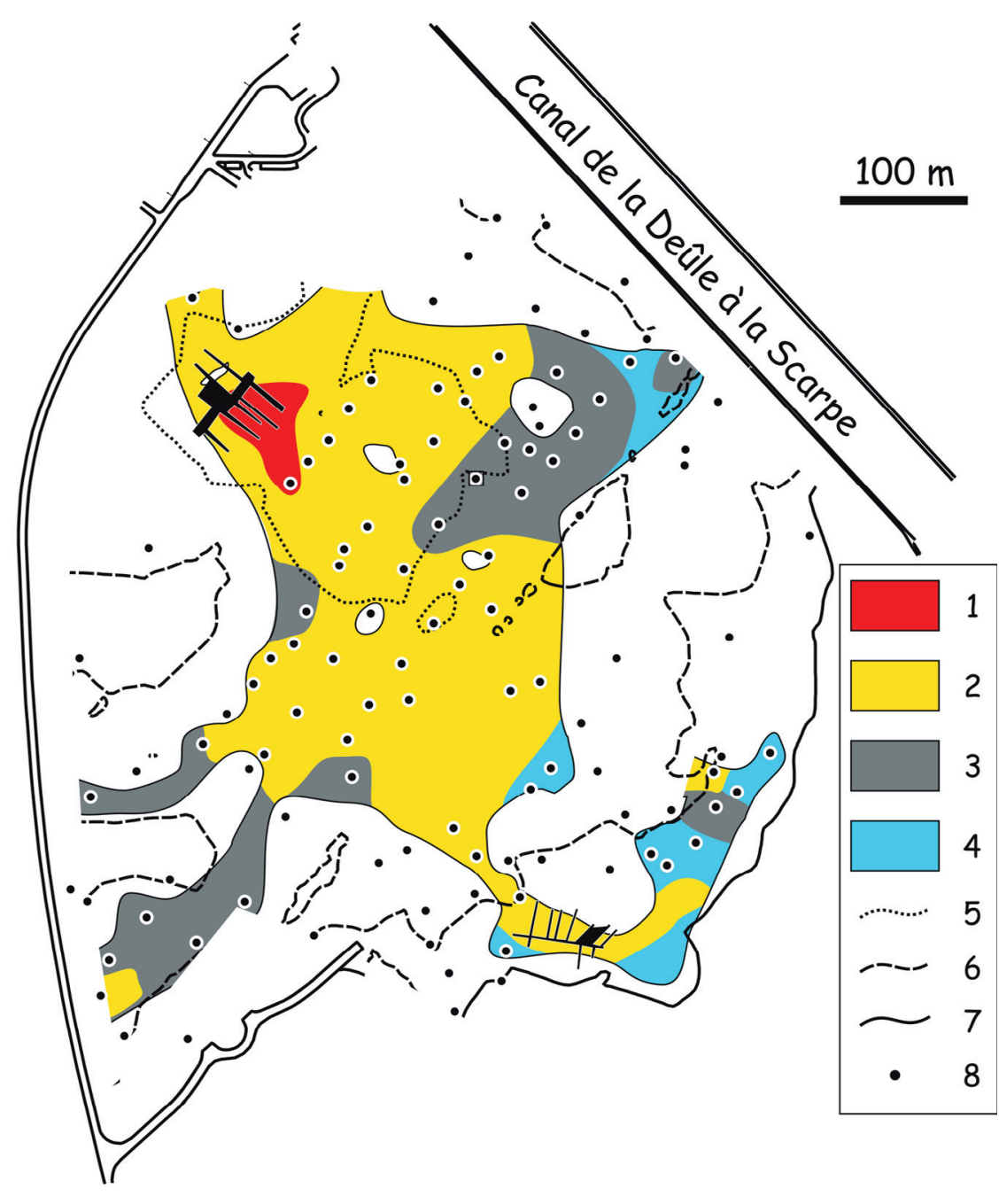

Fig. 4 : Extension approximative des alluvions sous les labours.

1) présence des trois niveaux tourbeux repères ; 2) extension du sédiment tuffacé et de l'horizon tourbeux supérieur noir; 3) présence de l'horizon tourbeux supérieur noir (sol Allerød) directement sur les sédiments loessiques (absence des sédiments tuffacés) ; 4) présence uniquement de l'unité 11 (colluvions du Dryas récent) ; 5) courbe de niveau $24 \mathrm{~m}$ IGN 69 ; 6) courbe de niveau 24,8 m IGN 69 ; 7) courbe de niveau $26 \mathrm{~m}$ IGN 69 ; 8) sondage ponctuel.

Fig. 4: Estimated extension of alluvium under plough horizon.

1) occurrence of three peaty marker horizons; 2) presence of both the tufa and the black upper peaty marker horizon; 3) black upper peaty marker (Allerød soil) overlying the loess sediments (lack of the calcareous tufa); 4) exclusive presence of unit 11 (Younger Dryas colluviums); 5) $24 \mathrm{~m}$ contour line; 6) $24.8 \mathrm{~m}$ contour line; 7) $26 \mathrm{~m}$ contour line; 8) deep test pit. 


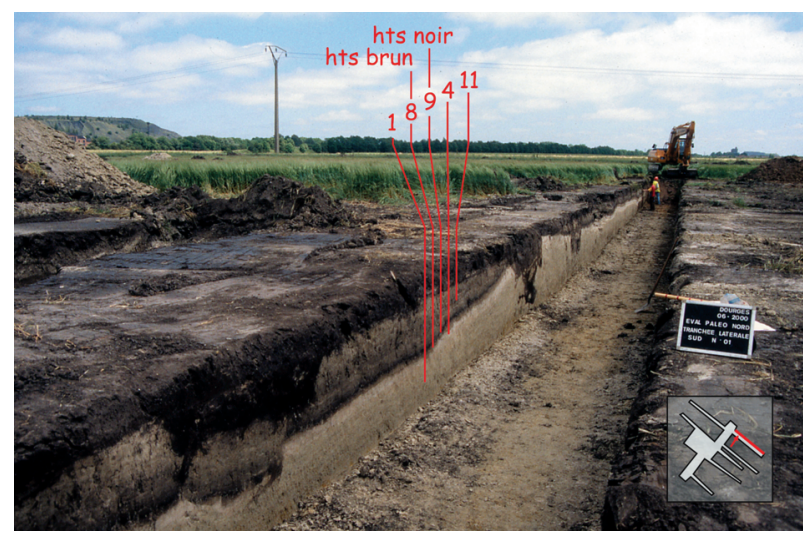

Photo 1 : Coupe de référence, extrémité nord.

Localisation en cartouche.

Photo 1: Reference section, northern extremity.

Location in the frame.

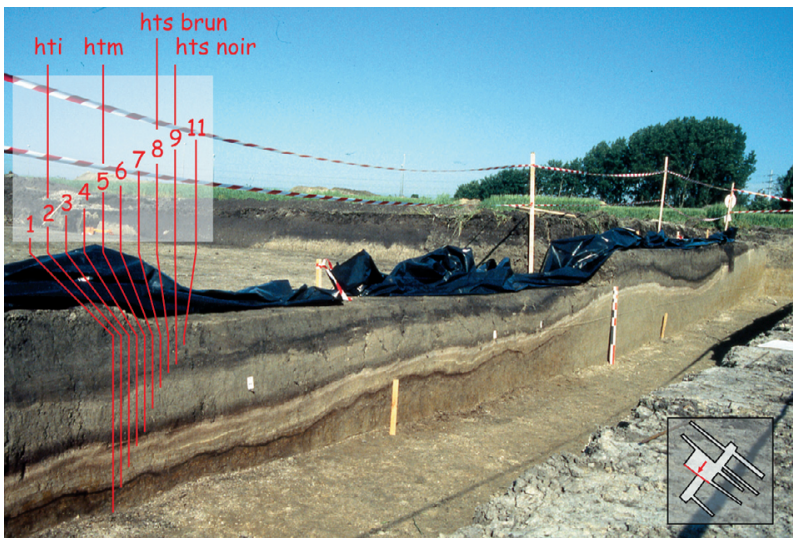

Photo 3 : Bordure nord du marais au niveau du site Federmesser : rive marquée.

Photo 3: Northern border of the marsh near the Federmesser site: a steep shore.

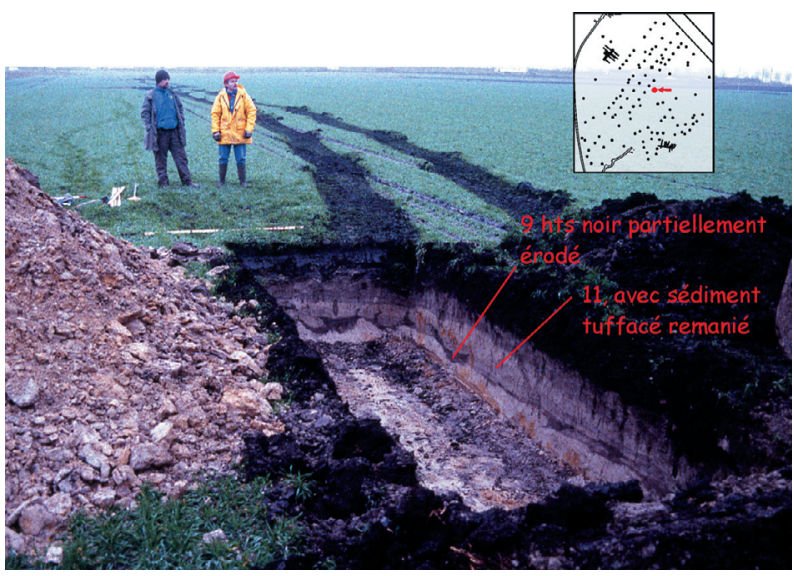

Photo 5 : Démantèlement localisé du sol humifère de l'Allerød. Localisation en cartouche.

Photo 5: Allerød soil breaking up.

Location in the frame.

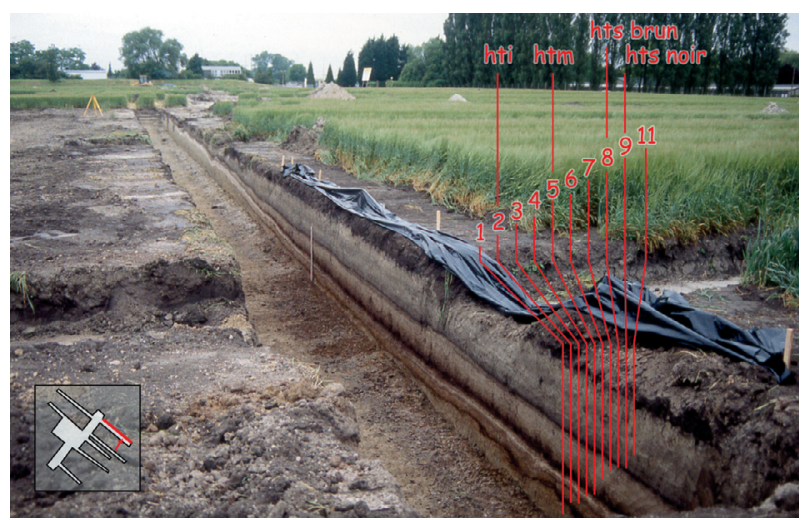

Photo 2 : Coupe de référence, extrémité sud.

Photo 2: Reference 1 section, southern extremity.

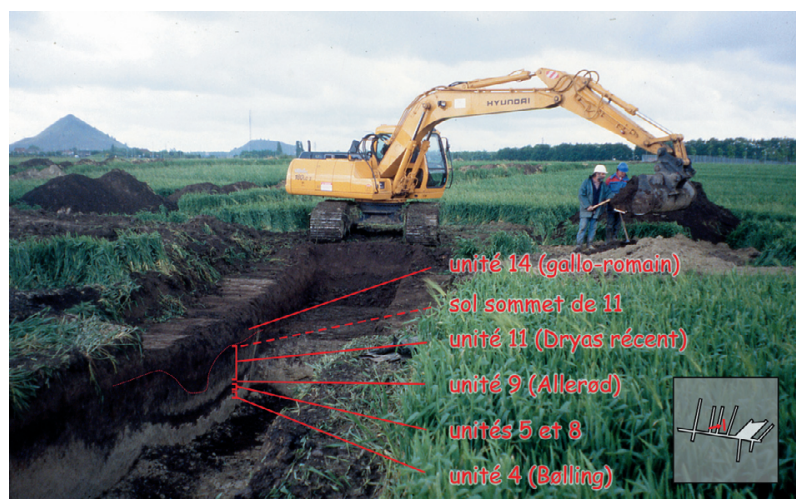

Photo 4 : Talweg hérité en bordure sud du marais, en sondage. Photo 4: Inherited talweg at the marsh south border, in a test pit.

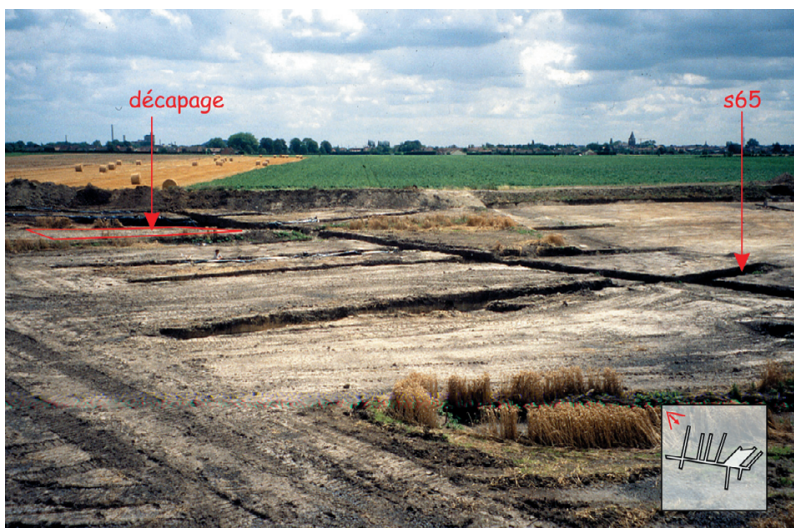

Photo 6 : Zone d'évaluation archéologique sud en bordure du marais, vue vers le versant et l'interfluve de Dourges.

s65 : localisation du crâne d'aurochs

Décapage : localisation de la fouille manuelle.

Photo 6: Southern archaeological area at the marsh border, view towards the slope and the Dourges interfluvium.

s65: wild ox skull.

Scrapping: location of the manual dig area. 


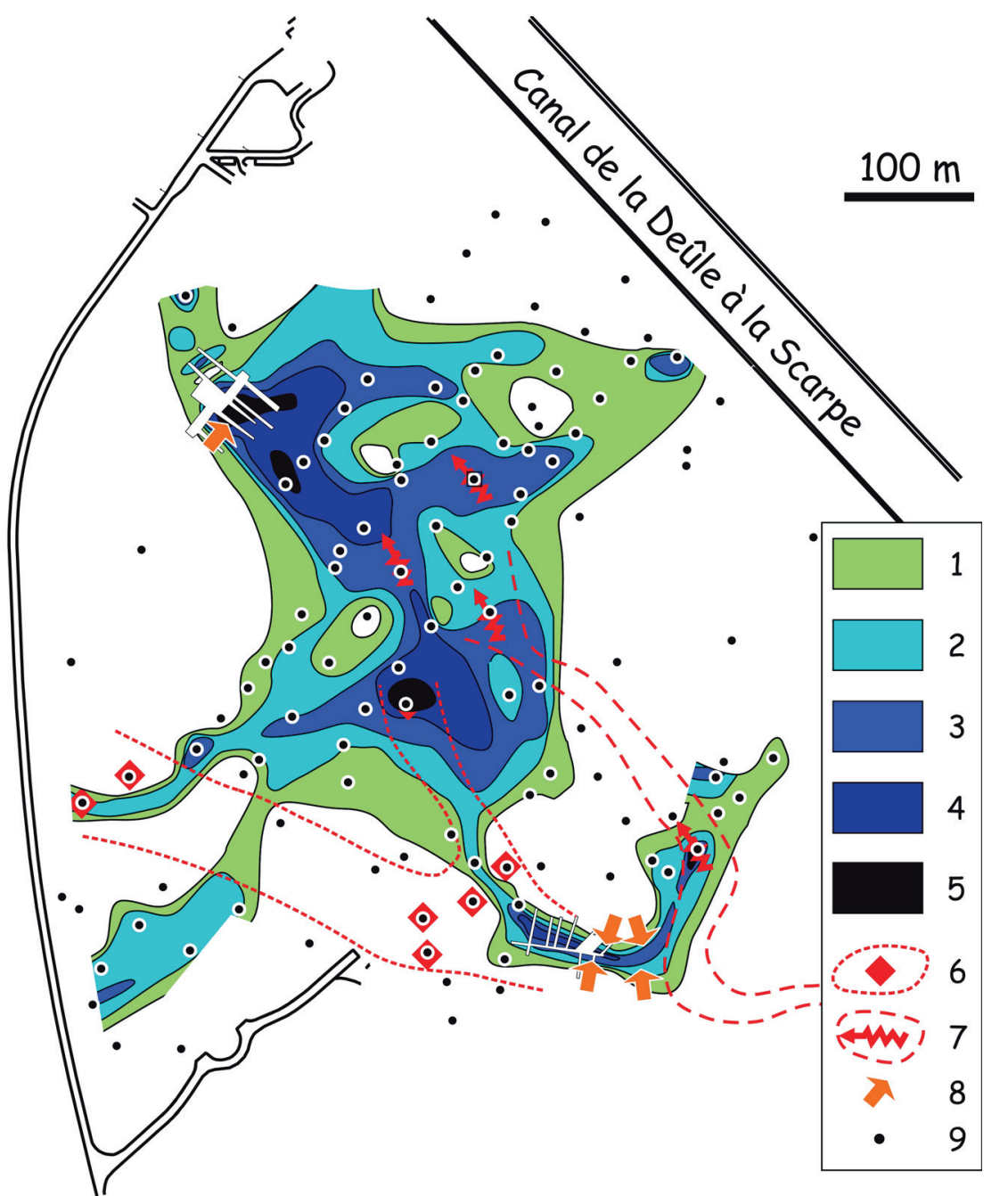

Fig. 5 : Epaisseur approximative des alluvions sous les labours toutes unités confondues sauf le labour et l'unité 1.

1) moins de $0,3 \mathrm{~m}, 2$ ) /de 0,3 à $0,6 \mathrm{~m}, 3$ ) de 0,6 à $0,9 \mathrm{~m}, 4)$ de 0,9 à $1,2 \mathrm{~m}, 5$ ) plus de $1,2 \mathrm{~m}$, 6) épandages de graviers de craie ou rognons de silex associés au limon loessique et extension possible d'un dépôt fluviatile grossier en provenance du versant, antérieur au Tardiglaciaire, 7) érosion fluviatile affectant le sol de l'Allerød et axe probable des écoulements provenant du versant (Dryas récent), 8) solifluxion affectant le sol de l'Allerød (Dryas récent), 9) sondage ponctuel.

Fig. 5: Estimated thickness of alluviums under plough horizon including all units except plough horizon and unit 1 .

1) less $0.3 \mathrm{~m}, 2$ ) from 0.3 to $0.6 \mathrm{~m}$, 3) from 0.6 to $0.9 \mathrm{~m}$, 4) from 0.9 to $1.2 \mathrm{~m}, 5$ ) more than $1.2 \mathrm{~m}, 6$ ) chalk gravels or flint blocks in loessy silt, and possible extension of a coarse fluvial sediment coming from the slope (previous to the Late Glacial), 7) fluvial erosion disturbing the Allerod soil and probable axis of flow from the slope (Younger Dryas), 8) solifluxion disturbing the Allerød soil (Younger Dryas), 9) deep test pit. ne semble pas toutefois que le tassement des tourbes et des tufs y ait été particulièrement important (le sédiment reste peu compact).

La fouille mécanisée des alluvions de la zone archéologique nord a démontré le caractère fermé de la dépression. La cartographie de l'épaisseur du dépôt alluvial met en évidence sa connexion avec un réseau de talwegs comblés (fig. 5). Le mieux marqué se situe au pied du versant, au droit de la zone archéologique sud (photos 5 et 6). Cette forme et son comblement ne se prolongent pas sur le versant. Le réseau hérité de talwegs et la présence d'éléments grossiers associés au limon loessique (épandages de graviers roulés, concentration de rognons de silex) (fig. 5) indiquent l'occurrence d'écoulements en provenance du versant. La topographie complexe du sommet du limon dans le marais est donc vraisemblablement l'héritage d'une activité fluviatile (eau de fonte provenant du versant) et de son interaction avec les apports éoliens du Pléistocène supérieur. Les apports éoliens ont d'ailleurs pu aboutir à la constitution de barrages responsables de changements de cours dans la partie amont des réseaux hydrographiques (bassin de la Reusel, sud des Pays-Bas, Van Huissteden et al., 1986). La région d'Hénin-Beaumont/Carvin, dans une zone de sédimentation loessique continue, sans relief important et en amont des réseaux hydrographiques organisés a vraisemblablement été un secteur propice à ce phénomène. Ceci peut expliquer la genèse de nombreuses dépressions fermées (fig. 1) qui ont favorisé les accumulations sédimentaires ultérieures sur des épaisseurs d'ordre métrique à pluri-métriques (Deschodt in Marcy, 2002 ; Lorin, 2003).

La stratigraphie observée dans le comblement du talweg, sur la zone archéologique sud, est aisément corrélée avec celle de la zone nord (fig. 2), d'autant plus que la jonction a été suivie en sondages (photo 3). Les faciès sont, sinon identiques, du moins très proches, avec toutefois la contraction des deux niveaux repères tourbeux supérieurs (HTM et HTSbrun) en une seule unité de limon brun tourbeux. Le niveau tuffacé équivalent de 4 présente, tout comme en zone nord, un faciès organique en partie supérieure et est très riche en malacofaunes. Il a livré quelques pièces lithiques isolées et les restes d'un aurochs de grande taille. La base de l'unité 11 présente des lits bien marqués sableux (traces d'écoulements). Un sol argileux sombre est développé en partie supérieure (fig. 3 et photo 5). Il contient un amas de débitage associé à des éléments de faune (aurochs). Un sol équivalent a vraisemblablement existé dans la zone nord mais a disparu dans les labours. En zone sud, la morphologie du talweg a permis le dépôt de deux formations plus récentes, de toute évidence holocènes au vu du matériel archéologique (unités 13 et 14). 


\section{3 - LES DATATIONS C14 : SÉDIMENTATION RAPIDE ET HIATUS}

Des datations sur faune effectuées en début d'évaluation archéologique ont abouti à des dates stratigraphiquement aberrantes. Par contre, une date effectuée sur des petits charbons de bois associés au niveau archéologique a donné une date concordante avec l' attribution chrono-culturelle du gisement (Federmesser). Par la suite le choix des éléments à dater a porté, dans la mesure du possible, sur les restes végétaux.

Des datations systématiques sur une colonne (tab. 1, fig. 7) permettent de distinguer trois phases de sédimentation séparées par deux hiatus : (a) la partie inférieure de la série (unités 2 à 6) est datée du Bølling (avec un taux de sédimentation moyen d'environ 0,7 à $0,8 \mathrm{~mm} \cdot \mathrm{an}^{-1}$, calcul basé sur la calibration à 1 sigma) ; (b) un hiatus chronologique que nous associons à la limite stratigraphique entre 6 et 7 (bien qu'un pas de $5 \mathrm{~cm}$ à la base de 7 n'a pas pu être daté) est attribué au Dryas moyen; (c) les unités 7 et 8 sont datées de l'Allerød, avec une vitesse de sédimentation d'abord relativement rapide $\left(0,4\right.$ à $\left.0,5 \mathrm{~mm} \cdot \mathrm{an}^{-1}\right)$ qui chute au cours du dépôt de l'unité 8 (environ $0,15 \mathrm{~mm}^{\mathrm{a}} \mathrm{an}^{-1}$ ) ; (d) un hiatus chronologique correspondant à la limite stratigraphique entre 8 et 9 , attribué à l'Intra Aller $\phi d$ Cold Period; (e) enfin le dépôt de l'unité 9 est daté de la fin de l'Allerød, le taux de sédimentation est très faible.

Les datations C14 ne nous permettent pas de détailler plus la chronologie Bølling-Allerød, vraisemblablement plus complexe que ne le laisse soupçonner la seule lecture des dates calibrées.

\section{4 - LA FAUNE}

\section{1 - L'ICHTYOFAUNE}

Des restes de poissons sont présents (unité 4, 6 et 7), parfois même en abondance (observés en fouille manuelle). Il s'agit de brochets (Esox lucius) et de perches (Perca fluviatilis) (détermination B. Clavel, INRAP/CRAVO). Les deux espèces sont caractéristiques des eaux peu profondes, plutôt limpides, avec présence de végétations aquatiques.

\begin{tabular}{|c|c|c|c|c|c|}
\hline provenance & $\begin{array}{c}\text { strati } \\
\text { (fig.5) }\end{array}$ & nature & $\mathrm{n}^{\circ}$ labo & date BP & cal BP (1 sigma) et remarques \\
\hline $\begin{array}{l}\text { évaluation, partie supérieure HTSb, } \\
\text { gisement Federmesser }\end{array}$ & 8 & ch. de bois & GrA-17427 & $11680 \pm 60$ & $13820-13480$ \\
\hline $\begin{array}{l}\text { évaluation, partie supérieure HTSb, } \\
\text { faune }(\text { bos }) \text { avec traces de décarnation }\end{array}$ & 8 & os & GrA-17637 & $9070 \pm 70$ & le collagène n'a pu être daté, date rejetée \\
\hline évaluation, reste de poisson & 4 & ichtyofaune & GrA-17428 & $7700 \pm 50$ & $\begin{array}{l}\text { le collagène n'a pu être daté, date aberrante } \\
\text { par rapport à celles de l'unité } 8 \text {, rejetée }\end{array}$ \\
\hline évaluation, pointe barbelée & 4 (sommet) & os & GrA-28820 & $11920 \pm 50$ & $14100-13800$ \\
\hline $\begin{array}{l}\text { colonne ech. } 6 \text {, de } 22,41 \text { à } 22,43 \mathrm{~m} \\
\text { IGN69 }\end{array}$ & 9 & débris végétal & GrA-23899 & $11030 \pm 70$ & $13150-12960$ \\
\hline colonne ech. 7 , de 22,37 à 22,41 & 8 (sommet) & débris végétal & GrN-28208 & $11250 \pm 70$ & $13410-13130$ \\
\hline colonne ech. 8 , de 22,33 à 22,37 & 8 (base) & $\begin{array}{c}\text { charbon de } \\
\text { bois }\end{array}$ & GrA-23824 & $11640 \pm 60$ & $13820-13460$ \\
\hline colonne ech. 9 , de 22,28 à 22,33 & 7 (sommet) & débris végétal & GrA-23900 & $10990 \pm 60$ & $\begin{array}{l}\text { date aberrante par rapport à la série } \\
\text { prélevée en continu, probable racine } \\
\text { provenant du sol unité } 9 \text {, rejetée }\end{array}$ \\
\hline colonne ech. 10, de 22,23 à 22,28 & 7 & débris végétal & GrA-23901 & $11720 \pm 60$ & $13840-13480$ \\
\hline colonne ech. 12 , de 22,13 à 22,18 & 6 & débris végétal & GrA-23903 & $12240 \pm 80$ & $15100-14050$ \\
\hline colonne ech. 14 , de 22,09 à 22,13 & 5 (sommet) & débris végétal & GrA-23904 & $8490 \pm 60$ & $\begin{array}{l}\text { date aberrante par rapport à la série } \\
\text { prélevée en continu, probable racine } \\
\text { holocène, rejetée }\end{array}$ \\
\hline colonne ech. 17 , de 21,91 à 21,94 & 5 (base) & débris végétal & GrA-23821 & $12310 \pm 70$ & $15050-14100$ \\
\hline colonne ech. 18 , de 21,86 à 21,91 & $\begin{array}{c}4 \text { (faciès } \\
\text { organique }\end{array}$ & débris végétal & GrA-23822 & $12230 \pm 70$ & $15050-13850$ \\
\hline colonne ech. 20 , de 21,76 à 21,81 & 3 & débris végétal & GrA-23905 & $12430 \pm 90$ & $15050-14050$ \\
\hline colonne ech. 21 , de 21,73 à 21,76 & 2 & débris végétal & GrN-28210 & $12590 \pm 150$ & $15550-14250$ \\
\hline sondage SP 32 (Renne) & $\begin{array}{c}11 / 9 \text { et } \\
\text { sous-jacent } \\
\text { remanié }\end{array}$ & os & - & - & pas assez de collagène \\
\hline fouille sud, faune & $\begin{array}{c}11 \\
\text { (sommet) }\end{array}$ & os & - & - & pas assez de collagène \\
\hline
\end{tabular}

Tab. 1 : Datations radiocarbones.

Les datations ont été réalisées par le Centrum voor Isotopen Onderzoek (université de Groningen, NL). GrN = datation conventionnelle, GrA = datation AMS.

Tab. 1: Radiocarbon dates.

Dates has been carried out by the Centrum voor Isotopen Onderzoek (Groningen univesity). GrN = conventional date, GrA = AMS date. 


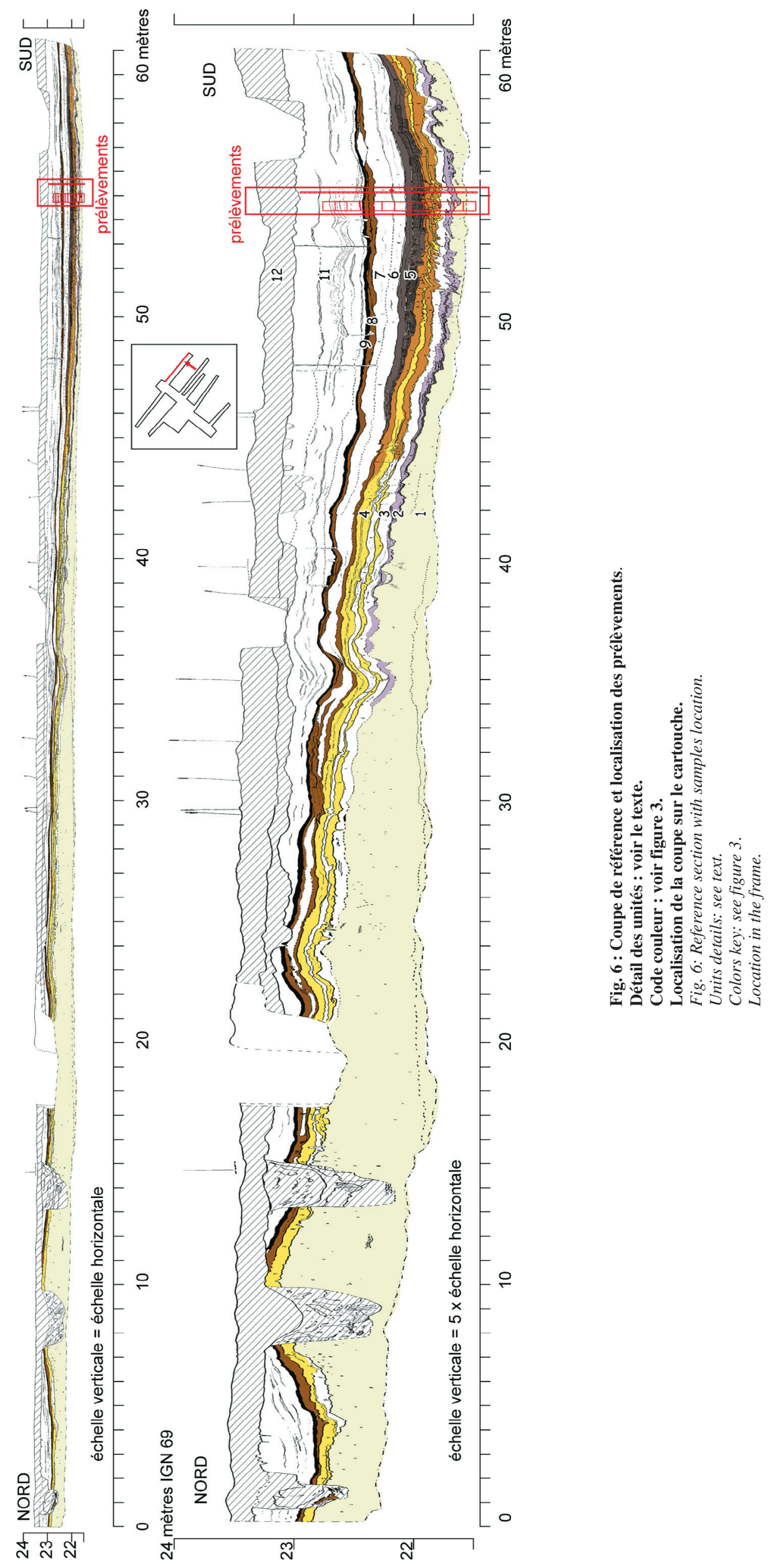




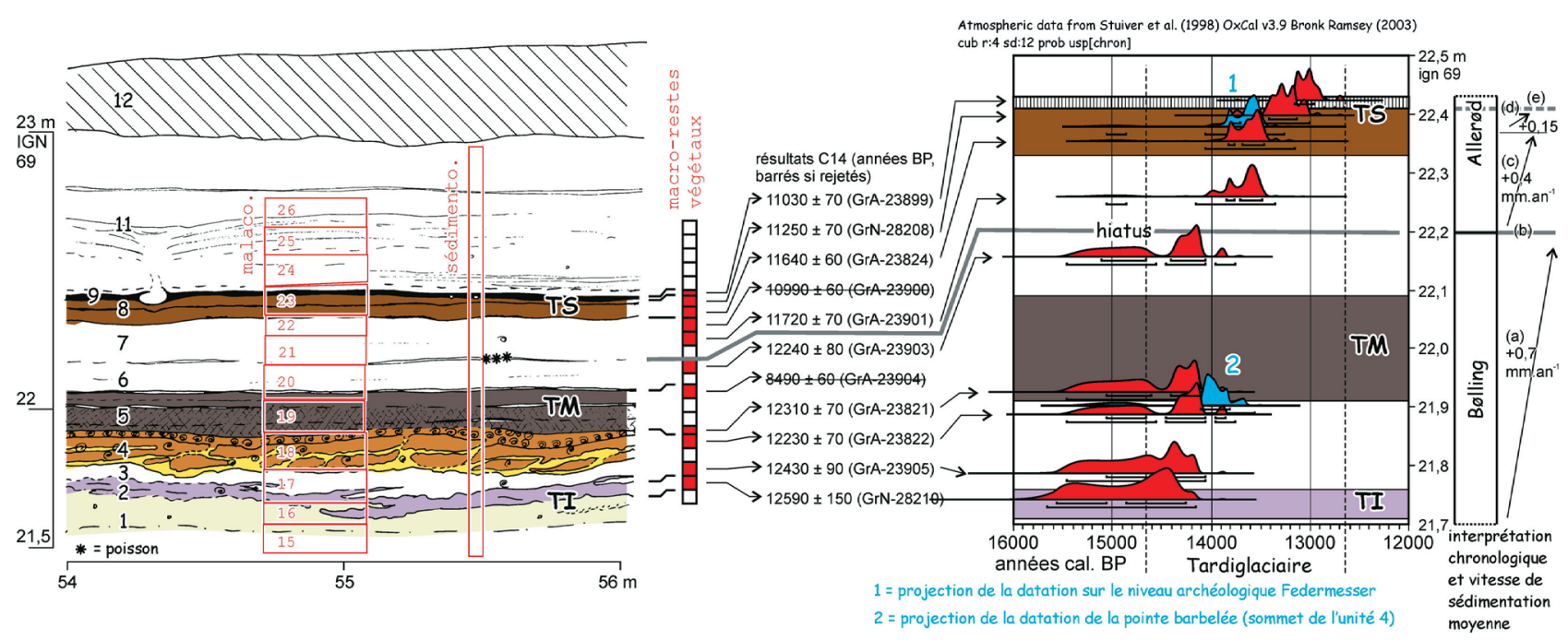

Fig. 7 : Présentation graphique des dates $\mathbf{C} 14$ calibrées et localisation sur la coupe.

Fig. 7: Calibrated radiocarbon dates scheme and location in the section.

\section{2 - LA MALACOFAUNE}

La série analysée se compose de douze échantillons d'environ 8 litres chacun pris en colonne continue selon une maille moyenne de $10 \mathrm{~cm}$, adaptée aux variations lithologiques (fig. 8). La conservation des coquilles est globalement bonne mais leur abondance s'est révélée très inégale (tableau 2). Sur les douze échantillons, huit ont livré moins de 50 coquilles sachant qu'un échantillon est considéré comme représentatif à partir d'une population approchant la centaine d'individus et que le seuil idéal pour les traitements statistiques se situe à 250 (Evans, 1972).

Qu'ils soient faibles ou abondants, les peuplements malacologiques de Dourges sont essentiellement composés par des mollusques aquatiques. Parmi les rares espèces terrestres, la mieux représentée est Oxyloma elegans (tab. 2), taxon de milieu palustre, fréquente en bordure des habitats d'eau douce (Kerney et al., 1983).
La variabilité des effectifs apparaît donc directement liée à des phases d'activité ou d'assèchement du plan d'eau. Ainsi trois épisodes d'installation d'un biotope aquatique sont mis en évidence par les malacocénoses dans les échantillons 16,18 et 22 (respectivement la partie supérieure de l'unité 1 , le tuf de l'unité 4 et la partie supérieure de l'unité 7), les deux derniers livrant des populations nettement plus développées que le premier (fig. 8).

Deux espèces sont dominantes dans l'échantillon 16 (partie supérieure de l'unité 1), Planorbis planorbis et Armiger crista (tab. 2). Elles sont caractéristiques de fonds vaseux pour la première et de la présence de plantes aquatiques pour la seconde (Adam, 1960). Les deux espèces sont capables de supporter des phases d'assèchement saisonnier et les faibles valeurs de diversité et d'abondance du cortège spécifique qui les accompagne laisse supposer la forte probabilité de cette éventualité. Cet épisode précède la première datation obtenue pour

\begin{tabular}{|l|c|c|c|c|c|c|c|c|c|c|c|c|}
\cline { 2 - 13 } \multicolumn{1}{c|}{} & $\mathbf{1 5}$ & $\mathbf{1 6}$ & $\mathbf{1 7}$ & $\mathbf{1 8}$ & $\mathbf{1 9}$ & $\mathbf{2 0}$ & $\mathbf{2 1}$ & $\mathbf{2 2}$ & $\mathbf{2 3}$ & $\mathbf{2 4}$ & $\mathbf{2 5}$ & $\mathbf{2 6}$ \\
\hline Oxyloma elegans & & 1 & 4 & & & & 1 & 6 & 1 & 6 & 3 & \\
\hline Vallonia pulchella & & & & & & & & & 1 & & & 2 \\
\hline Pupilla sp. & & 1 & & & & & & & & & & \\
\hline Limaces & & & & & & 1 & & & & & & \\
\hline Valvata piscinalis & & & & & & & 1 & & 1 & & & \\
\hline Valvata cristata & & & & & & & & 13 & & & & \\
\hline Radix sp. & 1 & 2 & 1 & 22 & 3 & & & 15 & 2 & 17 & 2 & 2 \\
\hline Lymnaea stagnalis & & & 3 & 56 & & & 1 & 19 & 1 & 3 & 1 & \\
\hline Planorbis planorbis & 9 & 54 & 24 & 160 & 2 & & 5 & 250 & 1 & 8 & 1 & \\
\hline Hippeutis complanatus & & & & 7 & & & & 14 & & & & \\
\hline Armiger crista & 14 & 102 & 28 & 18 & & & 1 & 25 & & 1 & & 2 \\
\hline Pisidium sp. & 1 & 1 & 18 & 273 & 5 & 2 & 6 & 61 & 1 & 11 & 3 & \\
\hline
\end{tabular}

Tab. 2 : Liste des malacofaunes. Tab. 2: Malacofaunas. 


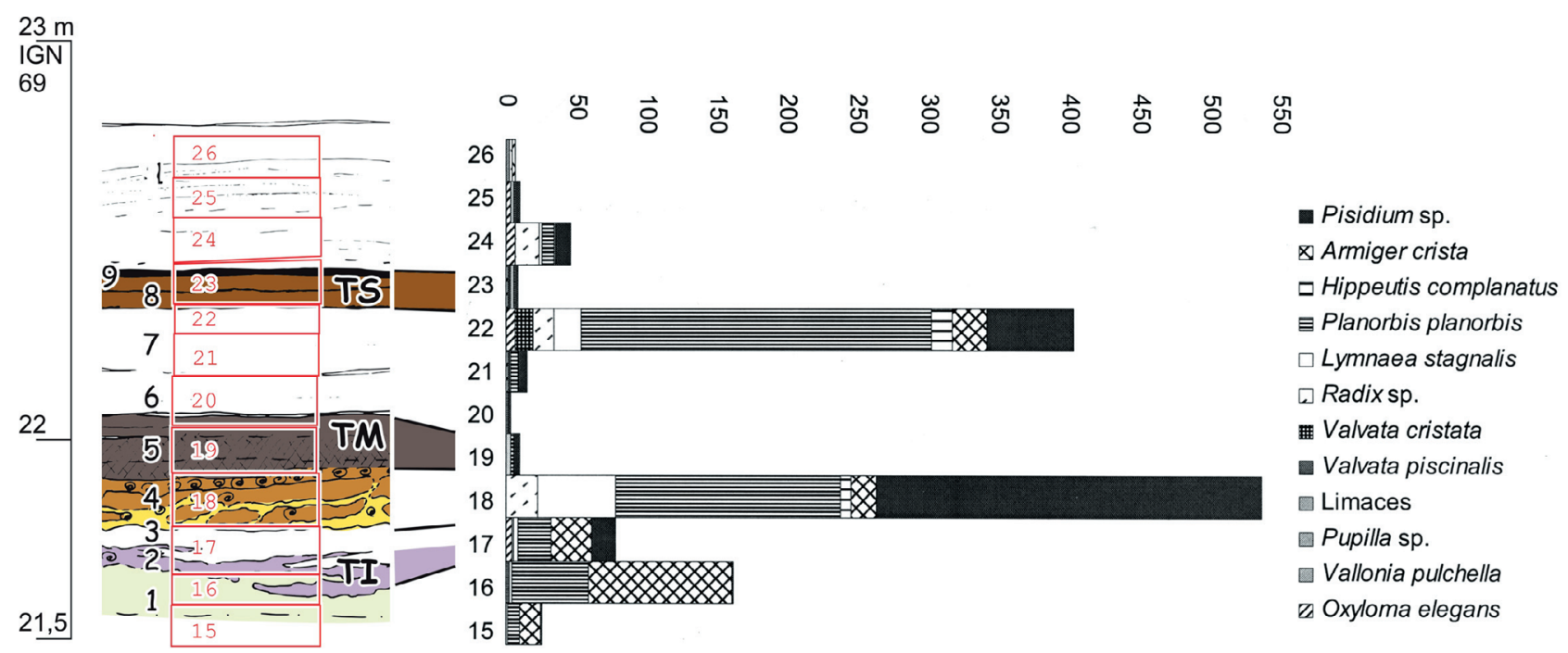

Fig. 8 : Répartition des espèces de mollusques dans les différents échantillons exprimée en valeurs absolues.

Fig. 8: Distribution of molluscs species within the samples expressed in absolute values.

la tourbe inférieure à $12590 \pm 150$ BP. Cette première tourbe $\mathrm{B} \emptyset$ lling correspond à une forte réduction des malacofaunes signalant un milieu aquatique moins développé et peu favorable à leur expansion (échantillon 17 : tab. 2 et fig. 8).

A l'inverse l'échantillon suivant, 18 (unité 4, tuf), est le plus riche de la séquence. La composition du cortège varie également par rapport aux précédents assemblages. Il se diversifie avec en particulier le fort développement des bivalves du genre Pisidium, celui des Lymnaeidae (Radix, Lymnaea stagnalis), tandis que $P$. planorbis reste abondant. Cet assemblage permet d'identifier un corps d'eau calme, voire stagnant, à fond vaseux mais pérenne sur l'année. De 19 à 21 (unité 5 «HTM » et unité 6) la quasi-disparition des malacofaunes (fig. 8) signale une phase d'assèchement (fin du Bølling - Dryas moyen).

Dans l'échantillon 22 (partie supérieure de l'unité 7) la reprise du développement malacologique n'en apparaît que plus contrastée. Avec un assemblage de plus de 400 individus (tab. 2) la malacocénose de ce niveau limoneux du début de l'Allerød (11720 \pm 70 BP), aussi diversifiée que celle de l'échantillon 18, est le témoin indubitable d'une phase aquatique.

Les quatre derniers échantillons (23 à 26) se rapportent au dernier niveau de tourbe daté de l'Allerød et au limon sus-jacent postérieur à $11030 \pm 70$ BP et attribué au Dryas récent. Ils contiennent des malacofaunes pauvres indicatrices d'un nouvel épisode de forte réduction des habitats aquatiques.

Malgré l'existence d'un référentiel malacologique régional bien calé pour le Tardiglaciaire (Limondin, 1995, Limondin-Lozouet et Antoine, 2001), les malacofaunes récoltées à Dourges ne permettent pas de proposer une attribution biochronologique des formations sédimentaires en raison du caractère essentiellement aquatique des assemblages, moins réceptifs que les terrestres aux variations climatiques. Les données malacologiques apparaissent, dans le cas présent, pertinentes à l'échelle locale. Elles rendent compte par la variation de la composition des cortèges et de l'abondance des effectifs, des phases successives de mises en eau et d'assèchement du plan d'eau. Ainsi, les épisodes de turbification et les stades froids correspondent à des abaissements prononcés du corps aquatique tandis que son développement est attesté lors des dépôts limoneux de phases interstadiaires. Ces observations sont en accord avec l'interprétation morphostratigraphique du gisement.

\section{3 - LA GRANDE FAUNE}

A l'occasion des sondages ou bien lors des fouilles réalisées à Dourges, plusieurs dizaines de vestiges osseux et dentaires de grands mammifères ont été découverts. La spécificité de ce gisement réside en la très faible densité des éléments par rapport à la surface considérée et l'absence de grande concentration d'ossements comme c'est souvent le cas dans d'autres contextes. L'analyse de toutes les pièces mises au jour nous a permis d'attribuer anatomiquement et spécifiquement l'essentiel du matériel.

Le nombre total de restes s'élève à 121 , provenant de plusieurs unités stratigraphiques (tab. 3). Six espèces ont été identifiées : l'Aurochs (Bos primigenius); le Cerf élaphe (Cerf elaphus); le Cheval (Equus sp.); le Chevreuil (Capreolus capreolus); le Cochon ou le Sanglier (Sus domesticus ou Sus scrofa) ; l'Élan (Alces alces). Par ailleurs, les niveaux rapportés à l'Allerød (niveaux 8 et 9) ont livré 7 os longs d'Oiseau.

C'est l'Aurochs qui est l'espèce la mieux représentée, avec 38 restes attribués sur 121 (soit 31,4\%). Il est présent dans les niveaux Bølling (4 et 5) et Allerød (9). On le trouve surtout dans le niveau 11, dont le contexte chronostratigraphique précis reste encore difficile à établir : soit du Dryas récent, soit un remaniement de pièces des niveaux Allerød sous-jacents. Le Chevreuil vient ensuite avec 15 pièces $(12,4 \%)$, dans 


\begin{tabular}{|c|c|c|c|c|c|c|c|c|c|}
\hline \begin{tabular}{|r|} 
NIVEAU \\
ESPECE (NR/NMIc) \\
\end{tabular} & 4 & 5 & $4 / 5$ à 8 & 8 & $8 / 9$ & 9 & 11 & $\begin{array}{l}\text { Hors } \\
\text { strati }\end{array}$ & TOTAL \\
\hline Aurochs & $9 / 1 \mathrm{a}$ & $3 / 1 \mathrm{a}, 1 \mathrm{j}$ & $2 / 1 \mathrm{j}$ & & & $5 / 1 \mathrm{a}$ & $19 / 1 \mathrm{a}, 1 \mathrm{j}$ & & $38 / 4 \mathrm{a}, 3 \mathrm{j}$ \\
\hline Cerf & $3 / 1 \mathrm{a}, 1 \mathrm{j}$ & $3 / 1 \mathrm{a}$ & & $2 / 1 \mathrm{a}$ & $1 / 1 \mathrm{a}$ & & & & $9 / 4 \mathrm{a}, 1 \mathrm{j}$ \\
\hline Cheval & & & & $1 / 1 \mathrm{a}$ & & $1 / 1 \mathrm{a}$ & & & $2 / 2 a$ \\
\hline Chevreuil & $1 / 1 \mathrm{a}$ & & & $2 / 1 \mathrm{a}$ & & $8 / 1 \mathrm{a}$ & $4 / 1 \mathrm{a}, 1 \mathrm{j}$ & & $15 / 4 a, 1 j$ \\
\hline Cochon ou Sanglier & & & & & & & $6 / 1 j$ & & $6 / 1 \mathrm{j}$ \\
\hline Elan & & & & & & & $1 / 1 \mathrm{a}$ & & $1 / 1 \mathrm{a}$ \\
\hline herbivore & 1 & 2 & 4 & 8 & 1 & 10 & 15 & 4 & 45 \\
\hline petit herbivore & & & & 2 & & & & 1 & 3 \\
\hline NR Total & 14 & 8 & 6 & 15 & 2 & 24 & 45 & 5 & 121 \\
\hline
\end{tabular}

Tab. 3 : Inventaire et dénombrement des taxons mammaliens identifiés à Dourges selon la position stratigraphique. Tab 3: Listing and counting of mammalian taxa from Dourges according to the stratigraphical location.

\begin{tabular}{|l|c|c|c|}
\hline Fémur Aurochs & Dourges & Biache (1) & Danemark (2) \\
\hline Longueur totale & $>550$ & & $470-524$ \\
\hline Longueur tête-condyles & 530 & & $440-482$ \\
\hline Diamètre Transverse max proximal & 188,5 & & $157-183$ \\
\hline Diamètre crânio-caudal tête & 69,9 & 70,53 & $61-69$ \\
\hline Diamètre Transverse min diaphyse & 64,6 & & $51-60$ \\
\hline Diamètre Transverse distal & 147 & & $122-146$ \\
\hline
\end{tabular}

Tab. 4 : Dimensions comparées du fémur de l'Aurochs de Dourges avec celles des Aurochs pléistocènes de Biache-Saint-Vaast et holocènes du Danemark.

1 : Auguste, 1995 ; 2 : Degerbøl et Fredskild, 1970.

Tab. 4: Comparison of dimensions of the Wild Ox femur from Dourges with the Pleistocene population from Biache-Saint-Vaast and the Holocene population from Danemark.

les niveaux Bølling (4), Allerød $(8,9)$ et le niveau 11. Le Cerf est présent avec seulement 9 restes $(7,4 \%)$, durant le Bølling $(4,5)$ et l' Allerød (8). 6 ossements d'un très jeune Suidé ont été découverts dans le niveau 11. Le Cheval n'est représenté que par deux pièces et uniquement durant l'Allerød $(8,9)$. Enfin, un frontal d'Élan portant le départ de ses deux bois a été mis au jour dans le niveau 11.

L'Aurochs se singularise très nettement par une très grande massivité de ses os, indiquant des individus de très grande taille comparable à celles des animaux couramment rencontrés durant le Pléistocène. La pièce la plus spectaculaire découverte à Dourges, dans le Bølling, est un crâne malheureusement incomplet (toute la partie inférieure est détruite) mais néanmoins suffisamment démonstratif pour avoir une idée de la forme présente (photo 7). L'envergure de ce crâne, chevilles osseuses comprises, est d'environ 1 mètre sur 1 mètre. Un fémur sub-entier très massif a également été découvert dans le Bølling (photo 8). Les dimensions prises sur quelques pièces permettent de confirmer la très grande taille de l'Aurochs de Dourges, comparable aux très grandes formes du Pléistocène comme à Biache-Saint-Vaast (Auguste, 1995), et supérieur même aux plus gros Aurochs holocènes connus au Danemark (Degerbøl et Fredskild, 1970) (tab. 4 à 6). L'estimation de la hauteur au garrot de l'Aurochs de Dourges indiquerait des animaux pouvant atteindre une stature de 2 mètres.

Une autre pièce osseuse très importante est le crâne d'Élan provenant du niveau 11 (photo 9). Très rare en contexte archéologique mais également paléontologique,

\begin{tabular}{|l|c|c|}
\hline Coxal Aurochs & Dourges & Biache (1) \\
\hline Longueur acétabulum & 95,6 & 95,13 \\
\hline largeur acétabulum & 106 & 107,33 \\
\hline
\end{tabular}

Tab. 5 : Dimensions comparées du coxal de l'Aurochs de Dourges avec celles des Aurochs pléistocènes de Biache-Saint-Vaast. 1 : Auguste, 1995.

Tab. 5: Comparison of dimensions of the Wild Ox coxal from Dourges with the Pleistocene population from Biache-Saint-Vaast.

\begin{tabular}{|l|c|c|}
\hline $\begin{array}{l}\text { Grand cunéiforme } \\
\text { Aurochs }\end{array}$ & Dourges & Biache (1) \\
\hline Diamètre dorso-plantaire & 47 & 52,42 \\
& & $43,9-60,8$ \\
\hline Diamètre transverse & 39,4 & 34,87 \\
& & $27,9-40,0$ \\
\hline Hauteur max & 22,2 & 21,78 \\
& & $17,0-26,6$ \\
\hline Hauteur min & 12,4 & 13,29 \\
& & $10,4-16,2$ \\
\hline
\end{tabular}

Tab. 6 : Dimensions comparées du grand cunéiforme de l'Aurochs de Dourges avec celles des Aurochs pléistocènes de Biache-SaintVaast.

1 : Auguste, 1995.

Tab. 6: Comparison of dimensions of the Wild Ox large cuneiform from Dourges with the Pleistocene population from Biache-Saint-Vaast.

cet animal est présent en Europe du Nord-Ouest durant le Tardiglaciaire avant de disparaître en migrant vers des contrées plus boréales au début de l'Holocène (Street et Baales, 1999). Une datation directe par 14C a été tentée sans résultat sur ce crâne, le recours à une datation AMS s'impose de par la faible quantité de collagène présent.

Les associations de grands mammifères identifiées dans les différents niveaux de Dourges sont intéressantes et permettent d'effectuer des comparaisons avec d'autres faunes et de replacer ce gisement au sein du monde tardiglaciaire de l'Europe du Nord-Ouest. En effet, les niveaux Bølling livrent l'association Aurochs/Cerf/Chevreuil, indiquant un milieu de type forêt claire sous un climat tempéré. On retrouve cette même faune en particulier en Angleterre et en Belgique (Cordy, 1992 ; Charles, 1998). Les niveaux Allerød voient le Cheval s'ajouter à l'association précédente, composition très classique pour cette période (Street et Baales, 1999). Pour cette période, nous avons pu comparer directement la faune de Dourges avec celle, 

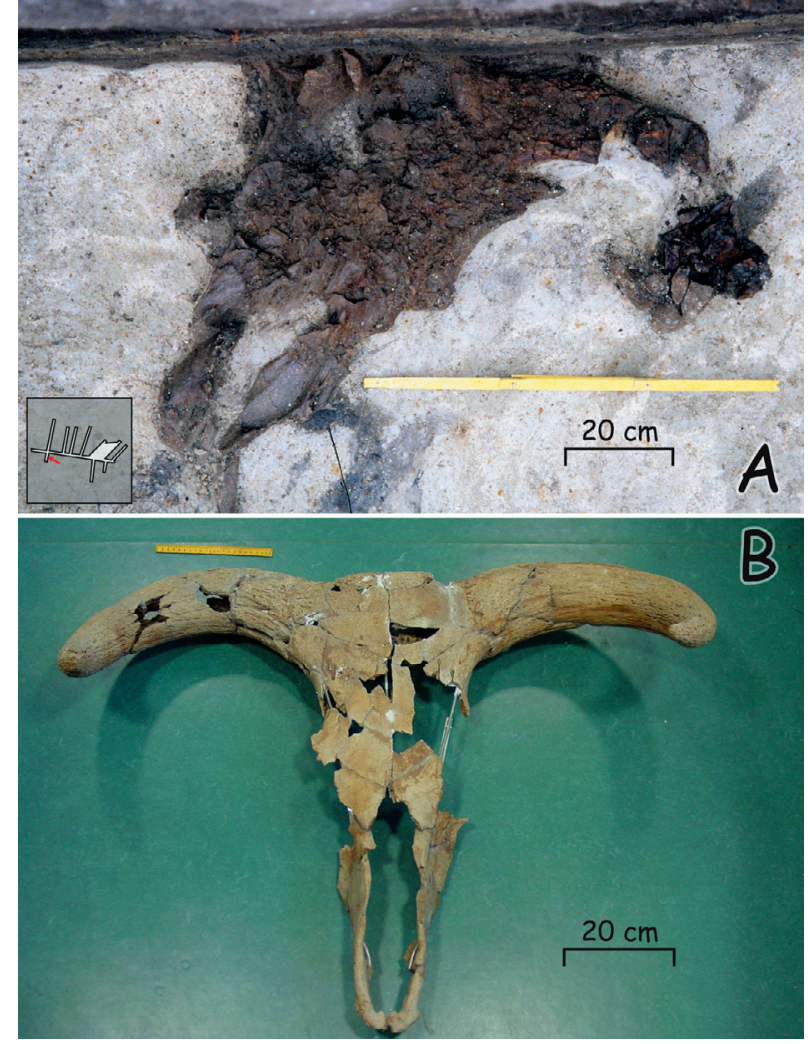

Photo 7 : Crâne d'Aurochs, Bølling, état in situ (A) et après restauration et chirurgie réparatrice (B). (photos : $P$. Millerat/AFAN et $P$. Auguste/CNRS).

Photo 7: Wild Ox skull, Bølling, in situ (A) and after restoration (B).

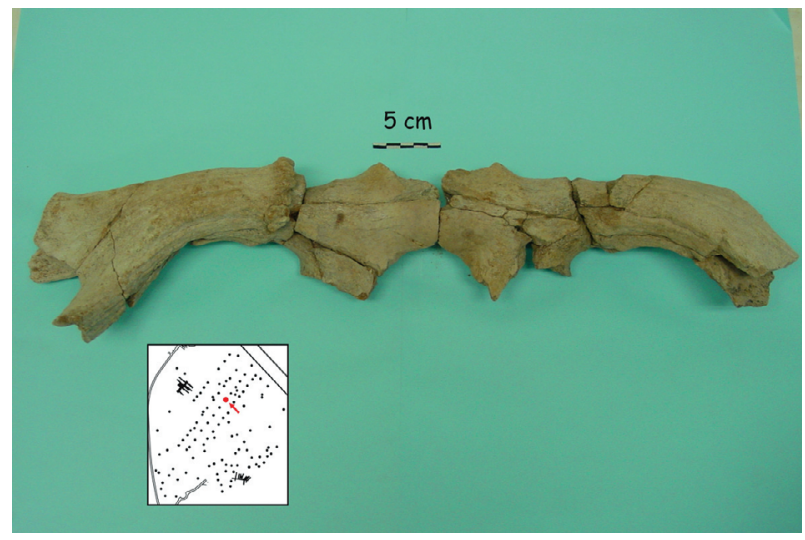

Photo 9 : Crâne d'Élan, Allerød ou Dryas récent (photo P. Auguste/ CNRS).

Photo 9: Elk skull, Allerød or Younger Dryas.

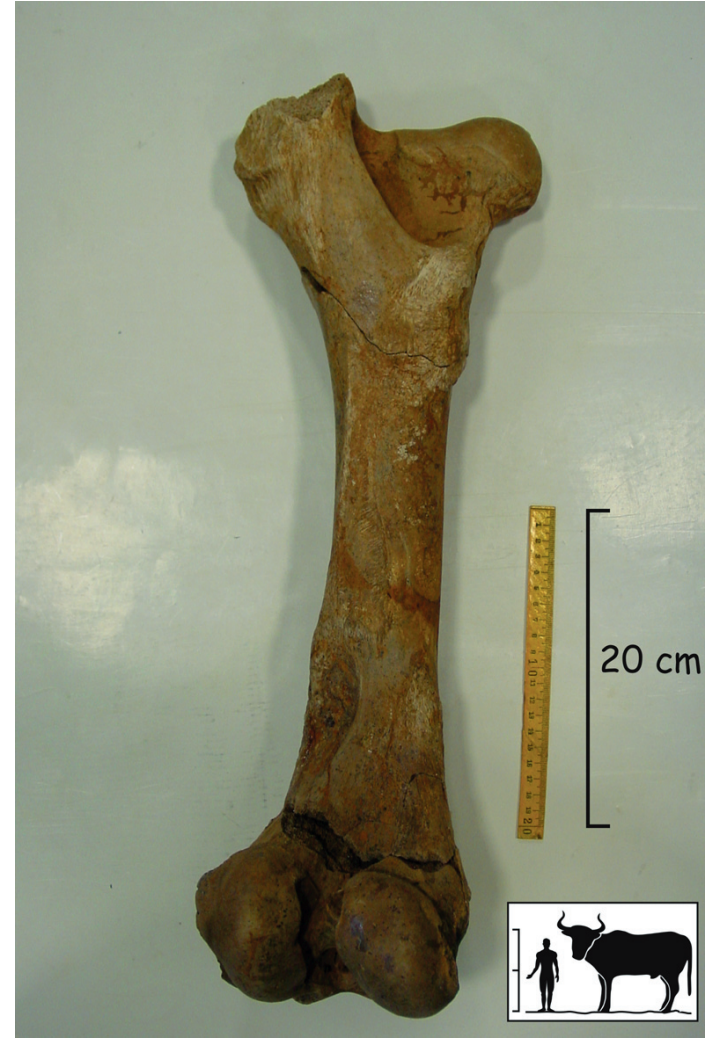

Photo 8 : Fémur d'Aurochs, Bølling (photo : P. Auguste/CNRS). Photo 8: Wild Ox femur, Bølling.

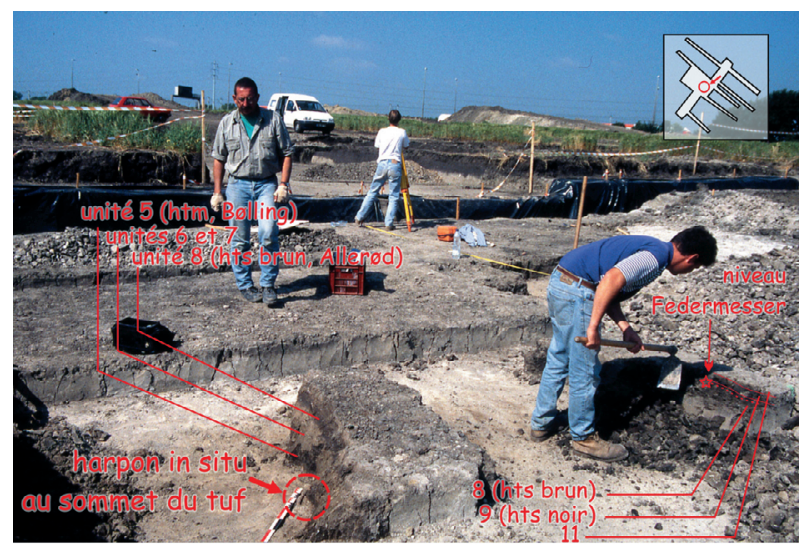

Photo 10 : Site nord en cours de fouille manuelle, localisation du niveau archéologique Federmesser et du harpon magdalénien.

Photo 10: Digging of the north site, location of the Federmesser level and the Magdalenian harpoon location.

Photo 11 : Harpon magdalénien in situ au sommet du tuf Bølling, unité 4.

Photo 11: Magdalenian harpoon in situ at the top of the Bølling tufa, unit 4. 


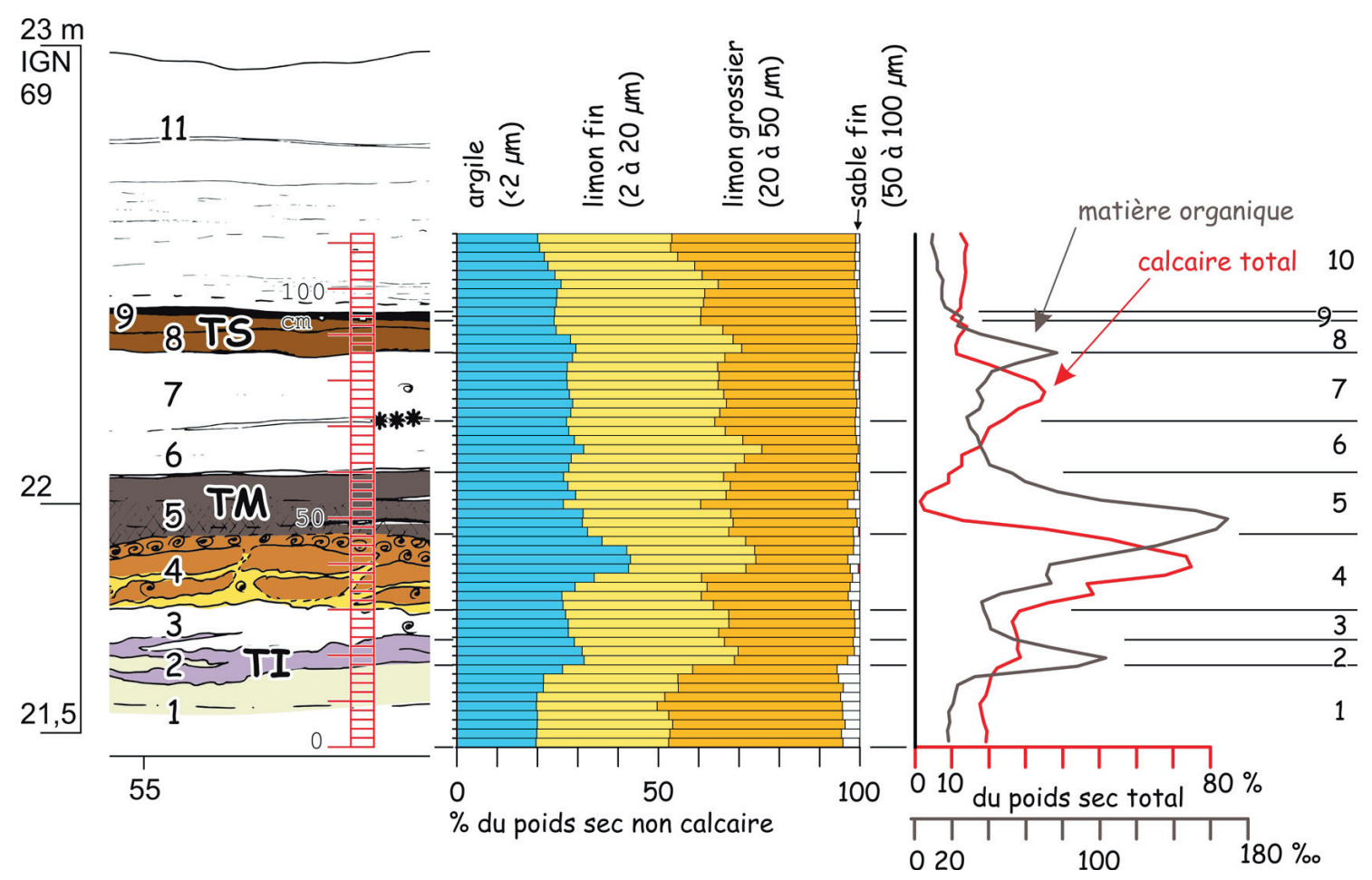

Fig. 9 : Analyses continue des sédiments (Laboratoire d'Analyses de Sols, INRA Arras). Fig. 9: Continuous analyses of sediments.

encore inédite, provenant des fouilles de Paule Coudret et de Jean-Pierre Fagnart à Conty, dans la Somme. Il apparaît ainsi une totale similitude entre les deux gisements, avec en particulier un Aurochs de très grande taille et un Cheval proche de la dernière forme pléistocène connue, Equus arcelini. Le climat caractérisé par ces taxons est tempéré, mais pas forcément aussi clément qu'au Bølling, le paysage s'apparente à une mosaïque de prairies et de zones boisées.

La faune provenant du niveau problématique 11, associant l'Aurochs, le Chevreuil, l'Élan et un Suidé peut éventuellement être interprétée comme étant en position secondaire, après une reprise de dépôts Allerød durant le Dryas récent. Dans ce contexte, l'Élan a tout à fait sa place, celui-ci faisant partie de la faune présente durant l' Allerød comme par exemple en Rhénanie (Street et Baales, 1999). La datation du crâne d'Élan s'avère toutefois indispensable afin de pouvoir trancher définitivement.

\section{5 - LES SITES ARCHÉOLOGIQUES}

Deux zones ont été fouillées manuellement. La première, en bordure nord du marais, a livré des industries sur faune (fragment de pointe en os barbelée, fragment de sagaie) et quelques éléments d'industrie lithique caractéristique du Federmesser. Au même endroit, légèrement plus bas, a été trouvé un harpon magdalénien. La superposition des deux gisements montre clairement l'attractivité de cette rive, probablement en raison de sa pente marquée vers le plan d'eau ou le marais. La deuxième fouille manuelle, en bordure sud du marais de Dourges, a permis la découverte d'un amas de débitage au sommet du limon gris (unité 11, fig. 3). Ce troisième gisement n'a pu être daté.

\section{1 - HARPON MAGDALÉNIEN}

Le fragment de harpon (fig. 10) le plus ancien provient du site nord, immédiatement sous la tourbe médiane, au sommet du tuf calcaire (photos 10 et 11). Il a été daté de $11920 \pm 50 \mathrm{BP}$ (tab. 1), compatible avec les datations encadrant la limite tuf (4) tourbe (5) $(12230 \pm 70$ et $12310 \pm 70 \mathrm{BP}$, fig. 7). Un burin sur troncature (futur burin de Lacam) a été trouvé un peu plus loin vers le centre de la dépression dans l'unité stratigraphique 3 (sous-jacente à l'unité 4 ou a été trouvé le harpon). Ces deux objets isolés signalent la fréquentation de la zone par des Magdaléniens, pendant la sédimentation tuffacée des unités 3 et 4.

Le harpon a été travaillé dans un fragment d'os long de grand herbivore, très probablement de l'aurochs. L'état de surface est excellent, voire exceptionnel, toutes les traces de façonnage sont parfaitement observables à l'œil nu. L'embase est de type à échancrure, située à l'extrémité distale de cette partie de la pièce. Elle empiète légèrement sur la partie proximale du fût barbelé. Cette échancrure est de facture assez grossière et témoigne probablement d'une réfection après une fracture accidentelle du système de ligature du lien reliant l'armature à la hampe. Ce type d'embase est relativement rare, mais a déjà été observé par ailleurs (Julien, 1982). Les barbelures sont aménagées sur une 


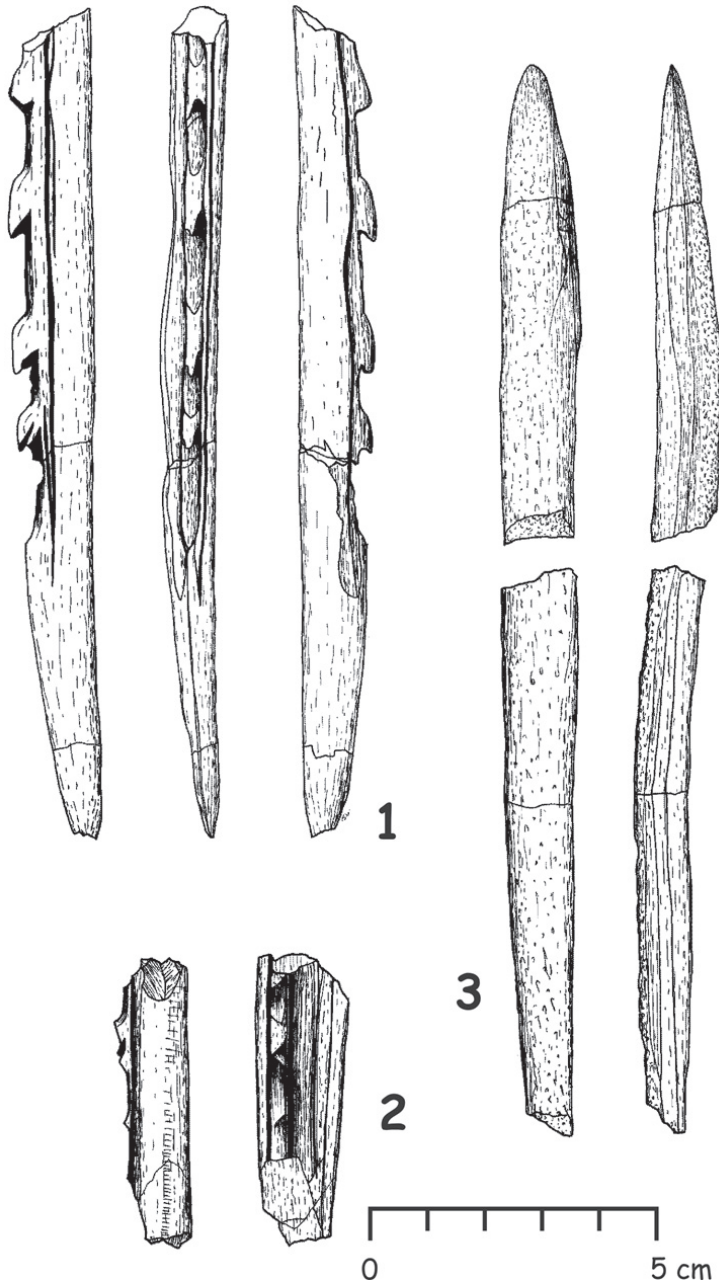

Fig. 10 : Pointes barbelées et sagaie. Dessins J. Lantoine (INRAP). 1) harpon magdalénien, 2) pointe en os barbelée Federmesser, 3) sagaie Federmesser.

Fig. 10: Barbed points and assegai.

1) Magdalenian harpoon, 2) Federmesser barbed bone point, 3) Federmesser assegai.

ailette qui fait saillie sur le fût sub-circulaire. Ces éléments essentiels ont été dégagés de l'ailette par incisions et enlèvements unilatéraux. La première barbelure est de plus petite dimension que les autres et elle pourrait avoir participé au système de ligature du lien après la réparation de l'embase. Cette hypothèse semble être confirmée par un petit surcreusement assez grossier de l'espace entre cette première barbelure et la suivante. La longueur de cette arme cassée $(144 \mathrm{~mm})$ témoigne de dimensions originelles dépassant largement la moyenne calculée $(130 \mathrm{~mm})$ pour l'ensemble des harpons entiers connus (Julien 1982). Conjointement aux caractéristiques de l'embase, c'est le style des barbelures et leur espacement sur le fût, qui autorisent le classement de la pièce magdalénienne dans la catégorie des harpons sensu stricto et de la rapporter au type $\mathrm{A} 2$ défini par M. Julien : pièce à un rang de barbelures moyennes relativement écartées. La présence de restes de poissons abondants dans les mêmes niveaux tuffacés, associée à la configuration topographique de la berge, rend plausible la perte de pièce lors de son utilisation pour la pêche (Julien, 1982), mais il est également possible que cette arme ait été utilisée pour la chasse aux grands herbivores dans les marais (Fagnart, 1997).

Outre cette pièce osseuse manufacturée, les niveaux Bølling ont livré 4 restes portant des marques anthropiques. Dans le niveau 4, un os long d'Aurochs est brûlé ; en 5, 2 bois de Cerf portent des indices nets de rainurages ayant très probablement été causés par l'extraction de baguettes ; au contact $4 / 5$ et 8 (zone sud), une hémimandibule d'Aurochs porte des marques de découpe situées sous le processus condylaire, témoignant $a$ priori d'une phase de dépeçage ou de désarticulation crâne/mandibule.

\section{2 - HALTE DE CHASSE FEDERMESSER}

Une fouille manuelle sur $1112 \mathrm{~m}^{2}$ a mis en évidence, sur la rive nord, des vestiges fugaces mais exceptionnels, au sommet de l'unité stratigraphique 8 (horizon tourbeux supérieur brun) (fig. 3). Elle a été complétée par une fouille mécanisée $\left(2434 \mathrm{~m}^{2}\right)$. Aucune structuration évidente ou latente n'est apparue. Cependant la nature même des découvertes (harpons, sagaies, armatures lithiques, ossements de grands mammifères dont un fragment d'os brûlé) et leur situation sur une zone légèrement plus haute en bordure de marais pourrait témoigner en faveur d'un site d'abattage d'herbivores. Il est intéressant d'observer ici une panoplie d'armes de chasse presque complète, avec ses pointes de flèche en silex à dos anguleux, sa sagaie et sa pointe en os barbelée (fig. 10). L'attribution culturelle est fournie par la pointe à dos anguleux et une lamelle à dos à fine retouche marginale qui toutes deux sont caractéristiques du techno-complexe à Federmesser, variante nordique du courant azilien. Ce techno-complexe apparaît en Europe septentrionale un peu avant l'interstade de l'Allerød et connaît son plein développement, en deux phases, lors de cette dernière oscillation tempérée (Fagnart, 1997). Cette attribution chrono-culturelle est en concordance avec les datations radiocarbones: $11680 \pm 60 \mathrm{BP}$ sur petits charbons de bois, dans le niveau archéologique lui-même et $11640 \pm 60$ à $11250 \pm 70 \mathrm{BP}$ au droit de la plus grande épaisseur de sédiment (tab. 1 et fig. 7).

La pointe barbelée est un fragment de fût de $50 \mathrm{~mm}$ de longueur. Elle a été fabriquée à partir d'un fragment de diaphyse de métatarsien d'Aurochs. Sa coloration brun clair est due au milieu tourbeux. Elle montre un état de surface remarquable qui permet l'observation à l'œil nu des traces de fabrication. Les barbelures ont été réalisées sur une sorte d'ailette en légère saillie sur le fût ; la gouttière longitudinale dorsale de l'os a été judicieusement mise à profit pour le dégagement de cette ailette. Les barbelures sont cassées, mais deux attaches sont encore discernables. Ici aussi, les barbelures ont été façonnées par des incisions et des enlèvements unilatéraux. Cette pointe en os barbelée devait être bien plus massive que le fragment de harpon magdalénien. Ce type d'arme est d'un type peu courant. Sa largeur de $11 \mathrm{~mm}$ est supérieure à la largeur de $7 \mathrm{~mm}$, limite à partir de et sous laquelle (les observations 


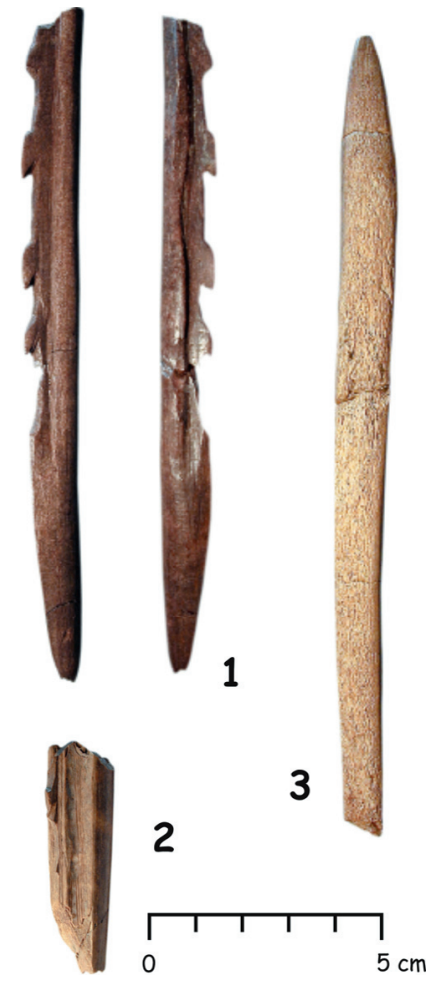

ethnoarchéologiques le prouvent) ces armatures barbelées sont fixes et souvent propulsées à l'arc (Weniger, 1992). Les caractéristiques de la zone marécageuse contemporaine, avec plan d'eau réduit (cf. infra) et l'absence de poissons semblent conforter l'hypothèse de la chasse.

Deux fragments d'une sagaie ont été trouvés à peu de distance l'une de l'autre (2 à 3 mètres). Ils se raccordent pour former une superbe pièce, presque complète (seule manque la base), d'une longueur totale de $183 \mathrm{~mm}$ (fig. 10 et photo 12). Elle est réalisée en bois de Cerf. La conservation en milieu tourbeux a donné une couleur brun clair à la pièce. L'état de surface est remarquable à tel point que tous les stigmates de fabrication sont visibles à l'œil nu. Le profil est presque rectiligne et la section sub-circulaire. Le travail de finition par polissage a fortement modifié le matériau naturel, de sorte que la spongiosa a pratiquement disparu. Les deux bords sont presque droits et parallèles et présentent les traces du travail de rainurage au burin de silex pour l'obtention d'une baguette dans le bois animal (splitting and growing). L'extrémité distale présente une pointe d'une acuité certaine, obtenue par l'amincissement progressif du fût sur les faces convexes (photo 13). Sur la partie mésiale de la sagaie, son profil est un peu courbe et tors, suite à la récupération des courbures anatomiques naturelles. La face externe montre une portion importante de spongiosa, tandis que la face interne est constituée de la compacta. Sur les deux bords, de très nettes stries parallèles dues au façonnage sont visibles. L'absence de base caractéristique rend impossible le classement dans un type précis.

Ce site paléolithique final est très intéressant à plus d'un titre. La faible densité et la nature des vestiges en font un site à «haute définition», dont l'analyse et

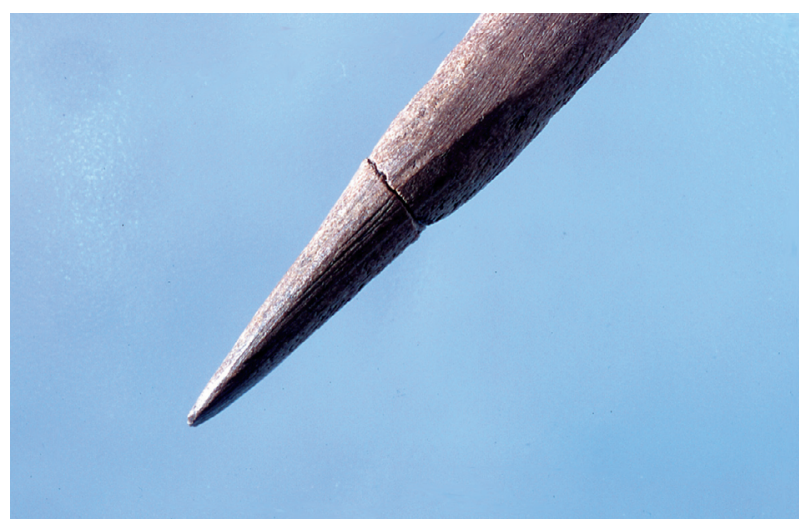

Photo 13 : Détail de la sagaie (photo J.M. PATIN/SRA). Photo 13: assegai detail.

$\leftarrow \quad$ Photo 12 : Pointes barbelées et sagaie (photos D. Bossut/INRAP). 1) harpon magdalénien, 2) pointe en os barbelée Federmesser, 3) sagaie Federmesser.

Photo 12: Barbed points and assegai.

1) Magdalenian harpoon, 2) Federmesser barbed bone point, 3) Federmesser assagai.

l'interprétation sont aisées en comparaison des grands sites. Ces derniers n'étant le plus souvent que le résultat de la récurrence de fréquentation d'un lieu. Le site de Dourges permet, quant à lui, de percevoir une activité bien définie et très ponctuelle dans le temps, il s'agit presque d'un cliché instantané du passé. La situation géographique du site en Europe du Nord-Ouest est également primordiale, elle est un relais entre différentes régions et pays où ce techno-complexe à Federmesser (ou d'autres plus ou moins contemporains) est bien documenté : Bassin parisien, Picardie, Grande-Bretagne, Belgique, Pays-Bas, Rhénanie. Il apporte également un nouvel éclairage sur le problème des pointes barbelées et harpons de la vallée de l'Escaut (Bostyn et Vallin, 1986 ; Fagnart, 1997). En effet, c'est près d'une quinzaine de ces objets qui ont été découverts au $19^{\text {ème }}$ siècle entre Isbergues et Anvers (Doize, 1952). Malheureusement on ignore pratiquement tout des conditions et contextes de ces découvertes anciennes.

\section{3 - L'AMAS DE DÉBITAGE DE LA ZONE SUD}

La zone sud a livré un amas de débitage associé aux ossements d'un aurochs. L'étude a permis le remontage (partiel) d'un rognon de silex, exploité dans l'optique d'une production laminaire (fig. 11). La matière première utilisée est un rognon de silex allongé d'une vingtaine de centimètres de long, doté d'irrégularités propres à ce silex issu de la craie locale. Le remontage concerne 20 pièces, réparties sur $3 \mathrm{~m}^{2}$ environ et inclus dans un petit sol noir développé dans les $20 \mathrm{~cm}$ supérieurs de l'unité 11 . Bien que le nucléus et les derniers produits extraits soient absents, il est possible d'entrevoir le schéma mis en place pour le débitage : après une régularisation rapide $\mathrm{du}$ rognon par enlèvements 


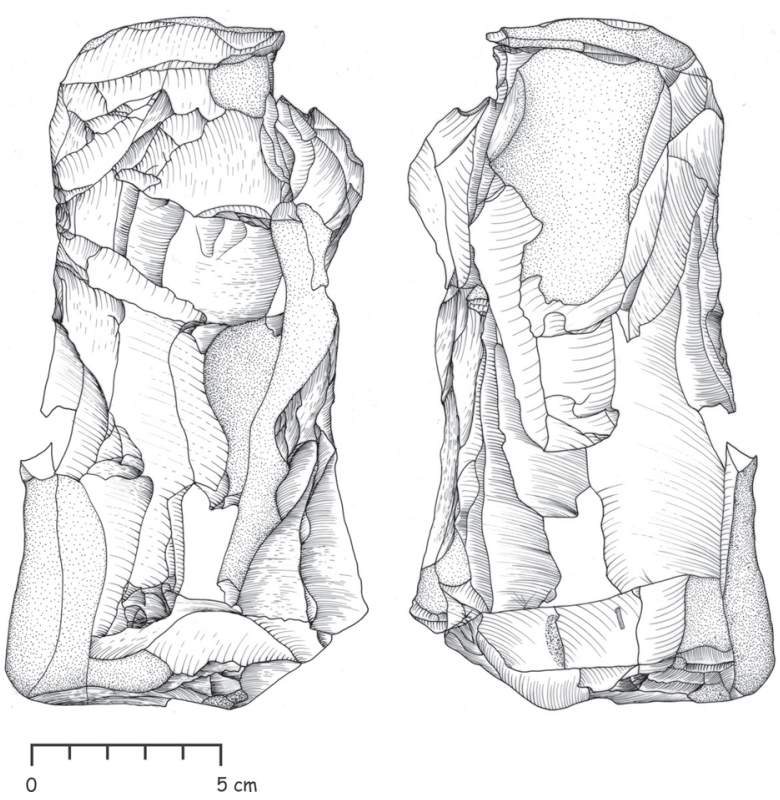

Fig. 11 : Remontage de l'amas de débitage, zone sud. Dessin J. Lantoine (INRAP).

Fig. 11: Refit knapping place, southern area.

d'éclats sur la surface corticale et une tentative de pièce à crête partielle utilisant une convexité du bloc, le débitage est effectué successivement à partir de 2 plans de frappe opposés. Les stigmates visibles sur les produits plaident pour un débitage réalisé en percussion directe au percuteur dur, éventuellement en percussion directe à la pierre tendre pour certaines pièces. Le résultat est une production laminaire irrégulière, les produits sont courts et relativement épais, les accidents de taille sont nombreux.

Trois os d'Aurochs portent des marques de boucherie : un tibia présentant à la fois une fracturation associée avec des stries de découpe ; un fémur portant une strie sous la tête articulaire ; un fragment d'os long brûlé.

Le site n'a pu être précisément daté. Il est au sommet des formations du dépôt du Dryas récent (attribution chronologique de l'unité 11, cf. infra) et est scellé par une tourbe gallo-romaine. Qu'il soit de l'extrême fin du Tardiglaciaire ou du début de l'Holocène, il est resté très longtemps en surface et la faune associée s'est révélée impropre à une datation $\mathrm{C} 14$ (tab. 1). Par ailleurs aucune comparaison chrono-typologique satisfaisante n'a pu être réalisée, ni avec le Paléolithique supérieur final, ni avec le Mésolithique, ni avec le Néolithique.

\section{5 - AUTRES TRACES ANTHROPIQUES}

Le niveau 9 (fin de l'Allerød) a livré deux os portant des stigmates anthropiques : un os long d'Aurochs présentant les caractéristiques d'une fracturation pour l'extraction de la moelle, ainsi qu'un os brûlé.

\section{6 - EVOLUTION DU « MARAIS DE DOURGES » AU COURS DU TARDIGLACIAIRE}

L'ensemble des données présentées nous autorise à reconstituer l'évolution du marais au cours du Tardiglaciaire (fig. 12).

\section{SOMMET DE L'UNITÉ 1}

Dans une topographie héritée (cf. supra «système morphosédimentaire »), formant cuvette et talwegs discontinus, une sédimentation limoneuse précède le premier horizon tourbeux. Elle ne se différencie de la couverture loessique ni par son faciès, ni par sa granulométrie (loess typique) (fig. 9). Elle s'effectue dans un plan d'eau avec assèchements temporaires, avec toutefois des conditions humides suffisamment marquées pour que le sommet de l'unité constitue le troisième échantillon le plus riche en malacofaunes (éch. 16, fig. 8). Antérieure à la première datation C14 $(12590 \pm 150 \mathrm{BP})$, l'attribution chronologique de ce dépôt est incertaine : il pourrait s'agir du remaniement du loess local, non encore stabilisé par un sol au cours d'une phase initiale du Bølling. Toutefois rien n' exclut une attribution au Pléniglaciaire.

PREMIÈRE FORMATION TOURBEUSE : PETITE ZONE HUMIDE DANS LA CUVETTE AU DÉBUT DU BØLLING

Le premier épisode de turbification (HTI, unité 2) est daté de $12590 \pm 150 \mathrm{BP}$, soit du début de l'interstade Bølling. Il s'effectue dans des conditions humides, certes, mais sans plan d'eau pérenne ni étendu comme l'indique la faible extension de l'unité 2 et son cortège de mollusques. L'humidité permet toutefois une décantation argileuse accrue par rapport au sédiment loessique sous-jacent (environ $30 \%$ pondéral de la fraction non calcaire, fig. 9). Cet antagonisme apparent entre une humidité moindre et un taux d'argile plus important par rapport au sommet de l'unité 1 pourrait être expliqué par le développement d'une couverture végétale continue stabilisant les versants loessiques mais permettant la migration des particules les plus fines vers la zone basse.

\section{EPISODE LACUSTRE ET DÉPÔT DE TUF}

Les unités 3 et 4 sont au contraire, au cours du Bølling (12430 \pm 90 à $12230 \pm 70$ BP), associées à un développement lacustre. Un plan d'eau pérenne prend son plein développement avec l'unité 4 . La précipitation chimique tuffacée y est intense (jusqu'à $75 \%$ du poids du sédiment sec, figure 9). Un pic marqué de sédimentation argileuse (plus de $40 \%$ pondéral de la fraction non calcaire) implique une eau calme, voire stagnante, donnée concordante avec le fort développement des malacofaunes, tant en effectifs qu'en diversité (cf. supra). Le plan d'eau est étendu (de l'ordre d'une 


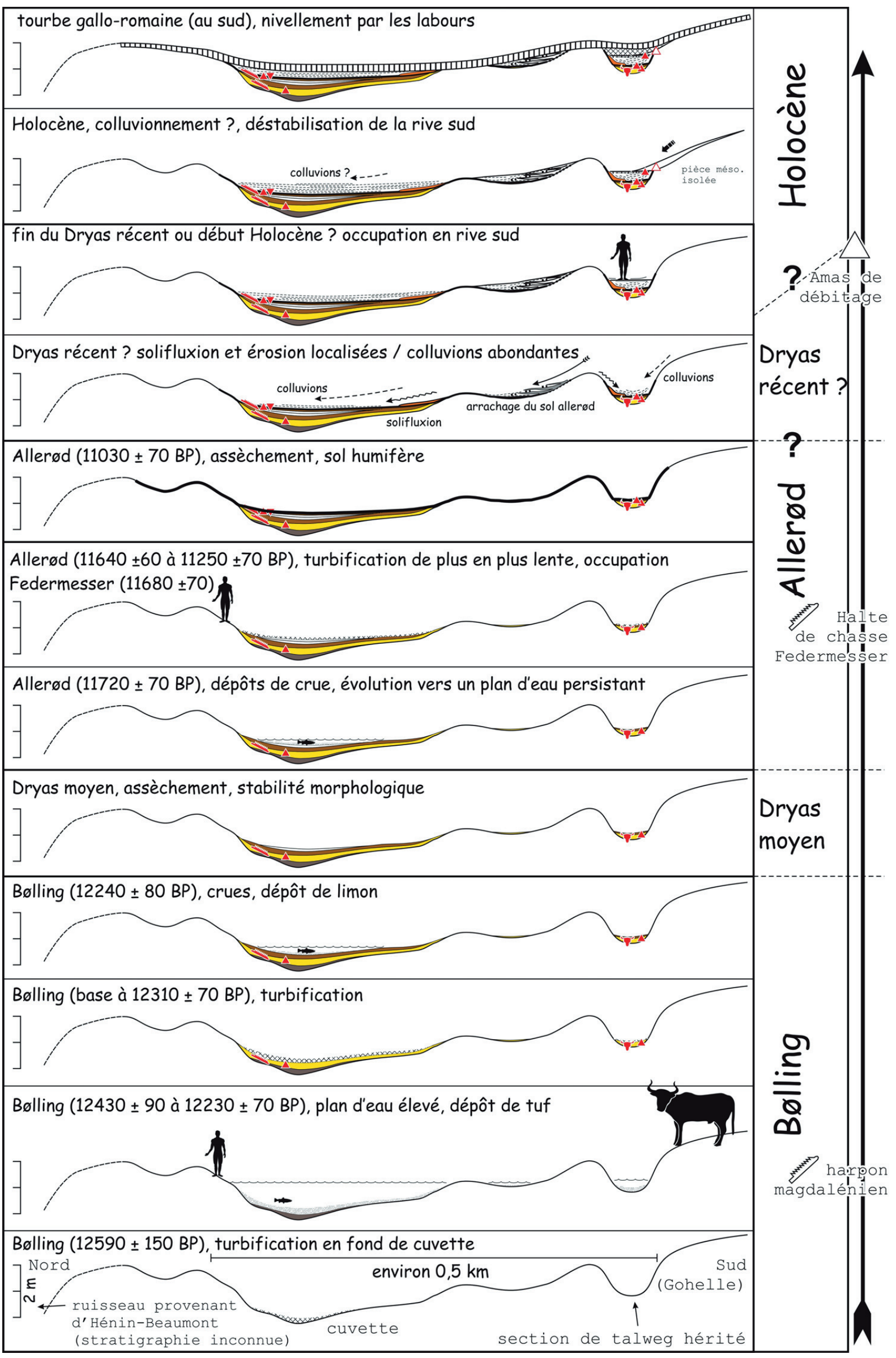

Fig. 12 : Evolution du marais depuis le Bølling. Fig. 12: Marsh evolution since the Bolling. 
dizaine d'hectares) mais peu profond. La topographie implique des connexions avec le réseau hydrographique et très vraisemblablement l'existence d'autres lacs contemporains dans les dépressions fermées de la région, à des altitudes proches (fig. 1). Brochets et perches y trouvaient un habitat idéal. Des aurochs fréquentaient la bordure du plan d'eau. L'attractivité du lieu sur les populations humaines est évidente. Les vestiges magdaléniens ont été trouvés dans les zones où la topographie du sédiment loessique engendrait les rives les mieux marquées : harpon en zone nord, associé à la tranche d'eau la plus importante (activité de pêche ?) et des éléments de faunes avec marques de boucherie en zone sud.

\section{DEUXIÈME FORMATION TOURBEUSE DU BØLLING}

La sédimentation lacustre est recouverte par une formation tourbeuse (HTM, unité 5) (12310 \pm 70 BP). Les effectifs malacologiques chutent, la sédimentation carbonatée devient quasiment nulle. Le lac disparaît. Seule l'aire la plus profonde est composée d'un sédiment avec fibres végétales. Le fait témoigne de la fluctuation de la nappe (saisonnière ?) avec seules les parties les plus basses gardant une humidité constante.

La présence de lamines claires dans la formation, ainsi que de brusques variations dans le détail de la granulométrie, indique une zone soumise à des apports détritiques épisodiques (crues). La partie supérieure de l'unité 5 est beaucoup moins organique que sa base, témoignant de conditions moins favorables à la turbification. Le fait peut être interprété comme un relatif assèchement. Toutefois, la sédimentation calcaire s'accroît progressivement à partir de ce niveau (fig. 9), bien avant la limite avec l'unité 6. Il s'agirait donc plutôt d'une reprise des apports détritiques et calcaires, avec une augmentation de la vitesse de sédimentation limitant le caractère organique du dépôt.

\section{FIN DU BØLLING : COURTES INONDATIONS}

A la fin du Bølling (12240 $\pm 80 \mathrm{BP})$, un nouveau dépôt limoneux lité (unité 6) recouvre la formation tourbeuse. La sédimentation est alors majoritairement détritique. La présence de restes de poissons prouve la présence d'un plan d'eau connecté au réseau hydrographique. L'inondation est toutefois de courte durée puisqu'elle ne permet pas le développement des malacofaunes aquatiques. Le marais subit donc de courtes inondations successives correspondant à des crues, avec piégeage de l'ichtyofaune. Il pourrait s'agir d'une zone de fraye, ce qui impliquerait une aire de végétation herbacée inondée au printemps, avec peutêtre une fréquence élevée du retour des crues.

\section{LE DRYAS MOYEN : UN HIATUS SÉDIMENTAIRE}

Les datations $\mathrm{C} 14$ révèlent un hiatus, entre les unités 6 et 7, correspondant à l'oscillation climatique froide du Dryas moyen (fig. 7 et 13). La limite correspond, sur le terrain, à un discret lit limoneux pulvérulent. L'épisode froid du Dryas moyen est donc également un épisode sec, sans apport sédimentaire ni turbification. Ce hiatus ne se marque pas dans les analyses granulométriques continues. L'abondance relative des poissons perçue à ce niveau (visibles en coupe, associés à la limite 6/7) ne peut s'expliquer ni par une recrudescence des inondations ni par l'assèchement d'un plan d'eau pérenne. Il pourrait s'agir simplement d'une concentration des restes antérieurs à la suite d'un remaniement superficiel du sommet de l'unité 6. La surface topographique du Dryas moyen serait alors peu ou mal protégée par la végétation (relative dénudation?). Aucune autre altération ou structuration n'a été notée et aucune pédogenèse ne semble souligner ce hiatus sédimentaire, contrairement à celui de la fin de l'Allerød (cf. infra).

\section{DÉBUT DE L'ALLERØD: RETOUR PROGRESSIF À DES CONDITIONS HUMIDES}

L'unité 7, datée du début de l'Allerød (11720 \pm 70 BP), présente un faciès très proche de celui de la fin du Bølling : limon discrètement lité, avec ichtyofaune. Son extension est similaire. Les analyses malacologiques et les mesures de calcimétrie montrent toutefois une bi-partition : la partie inférieure est comparable à 6 , bien que légèrement plus calcaire, mais la partie supérieure correspond au second pic de sédimentation tuffacée (jusqu'à plus de $40 \%$ pondéral) avec un nouveau développement de la malacocénose aquatique. Le fait témoigne du retour à un plan d'eau persistant sinon permanent au sommet de l'unité. Il est, cette fois, limité à la cuvette et se développe en continuité avec le régime de crues perçu dès la fin du Bølling.

\section{SÉDIMENTATION TOURBEUSE DE L'ALLERØD}

Comme au Bølling avec le passage des unités 4 à 5 , le sédiment 7 passe à un dépôt tourbeux (unité 8, HTS brun). Son faciès est d'ailleurs similaire à la tourbe médiane 5 avec laquelle elle se confond latéralement, en l'absence des unités 6 et 7. Le taux de sédimentation décroît fortement et les quelques centimètres de la formation tourbeuse supérieure correspondent à une grande partie de l'Allerød. Le liséré sombre, proche de 9, au sommet de l'unité, suggère d'ailleurs un arrêt temporaire de la sédimentation tourbeuse. De plus, le diachronisme de la limite supérieure entre la date obtenue en périphérie de la cuvette dans le niveau Federmesser $(11680 \pm 60 \mathrm{BP})$ et au maximum de dilatation $(11250 \pm 70 \mathrm{BP})$ implique une sédimentation limitée à la seule zone basse à la fin de la période.

FIN DE L'ALLERØD : ASSÈCHEMENT DE L'INTRA ALLERØD COLD PERIOD ET SOL HUMIFÈRE

La fin de l'Allerød présente un bilan sédimentaire faible : à peine quelques centimètres entre le sommet 


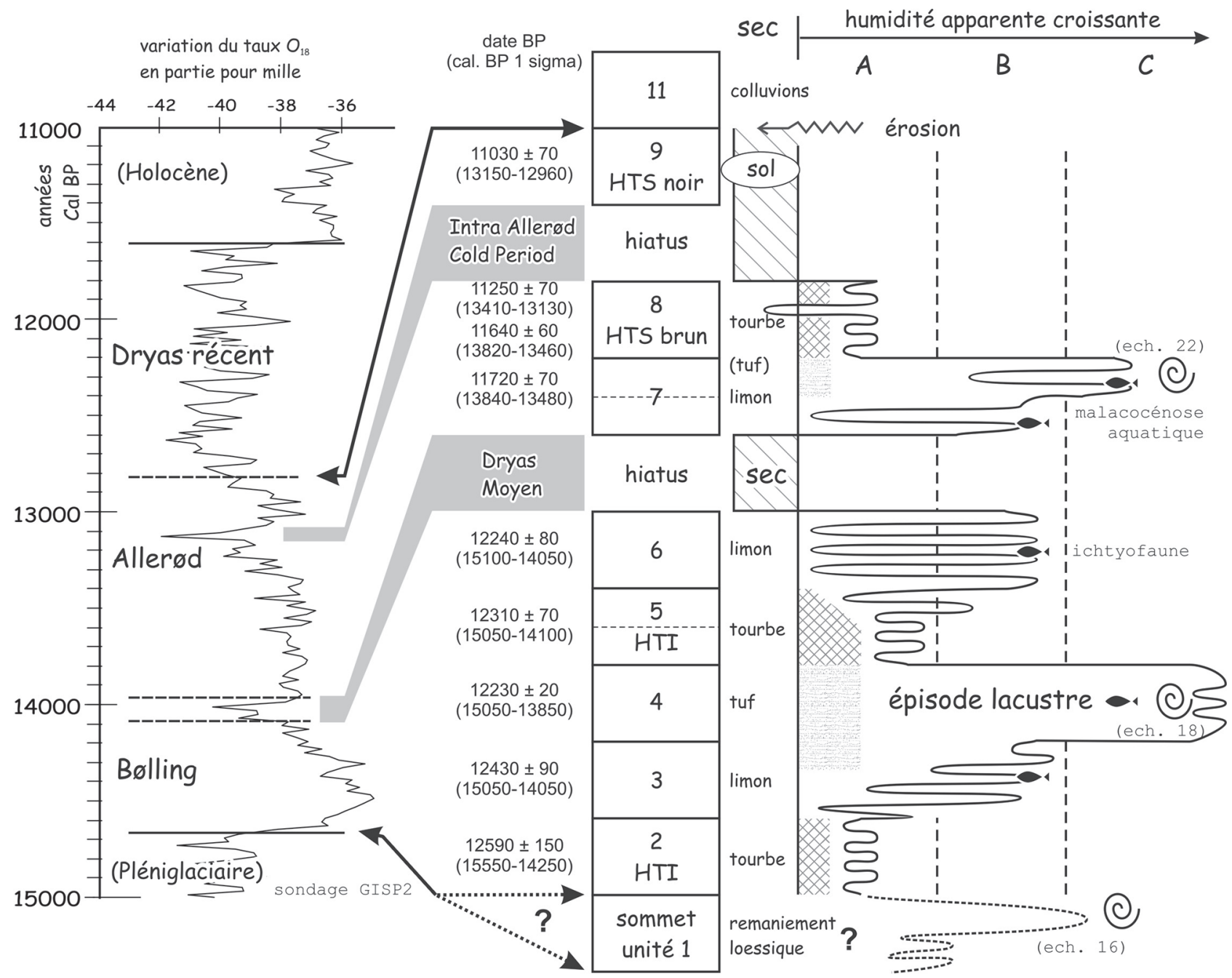

Fig. 13 : Evolution hydrologique du marais de Dourges et comparaison avec les variations O18 dans les glaces du sondage GISP2.

A) zone humide, possible petit plan d'eau saisonnier, sédimentation tourbeuse, B) plan d'eau temporaire avec présence de poissons, connexions avec le réseau hydrographique en période de crue, sédimentation majoritairement détritique, C) plan d'eau pérenne ou bien développé sur l'année, malacocénose aquatique, connexions durables avec le réseau hydrographique, sédimentation à dominante tuffacée.

Fig. 13: Hydrological evolution of the Dourges marsh versus O18 variations of the ice core GISP 2.

A) humid zone, seasonal water body, peat accumulation, B) temporary waterbody with fishes, link with river pattern during floods, mainly detritic deposits, $C$ ) permanent water body, aquatic malacocoenosis, permanent link with river pattern, tufaceous sedimentation.

de l'unité 8 daté de $11250 \pm 70$ et l'unité 9 (horizon tourbeux supérieur noir) datée de $11030 \pm 70$ BP. La genèse de l'horizon sombre n'est pas liée à des conditions humides. Il se développe sur la totalité de la zone sondée. Il est interprété comme un horizon superficiel de sol humifère (prairie ?).

\section{PHÉNOMÈNES ÉROSIFS LOCALISÉS ATTRIBUÉS AU DRYAS RÉCENT}

L'unité 11 se dépose sur l'horizon noir de l'Allerød (unité 9) sans érosion perceptible, à l'exception toutefois de deux phénomènes localisés :

a) Vers la périphérie de la cuvette nous observons sur quelques zones à pentes fortes un limon vivement coloré (oxydation, couleur orangé), délimité en partie supérieure (non systématiquement) et inférieure (systématiquement) par un horizon sombre en continuité avec l'horizon noir Allerød. Son épaisseur est modérée. Il peut présenter un bourrelet convexe dirigé vers le bas. Une coupe du site nord présente une succession de deux de ces dépôts. Autant de caractéristiques qui permettent d'interpréter l'unité 11 comme résultant d'un phénomène de solifluxion progressant sur l'horizon humifère et soulevant le chevelu racinaire. La texture limoneuse, particulièrement gélive, a favorisé le phénomène (Bertran et Coutard, 2004) qui reste cependant extrêmement localisé.

b) Quelques sondages ont clairement montré le démantèlement de l'horizon humifère Allerød par des écoulements fluviatiles (photo 5). Ils se situent dans l'axe du débouché d'un talweg descendant du versant (fig. 5). Les niveaux sous-jacents sont incisés et réintégrés à l'unité 11, expliquant les variations rapides de couleur et de calcimétrie de ce dernier. En bordure sud du marais, sur la zone fouillée, la base de l'unité 11 est sableuse et litée. Le talweg est donc emprunté par des écoulements provenant du versant qui, ici, ne suffisent 
toutefois pas à inciser le sol. A cet endroit, les phénomènes de solifluxion précèdent les écoulements fluviatiles.

Nous assistons donc à une phase de déstabilisation du versant qui affecte ponctuellement le sol de l'Allerød par un gélifluxion puis par une érosion fluviatile. Les colluvions contribuent à protéger les formations antérieures.

\section{EVOLUTION ULTÉRIEURE}

Le limon gris (unité 11), interprété comme colluvions, est irrégulier en épaisseur. Il tend à combler et niveler la microtopographie. La base est corrélative d'une déstabilisation des versants limoneux au Dryas récent. La granulométrie de la partie inférieure de l'unité indique une baisse du taux d'argile (20\% pondéral) après des taux systématiquement à plus de $25 \%$ dans les sédimentations lacustres et palustres précédents (fig. 9). Si ce n'est la très faible part de la fraction sableuse, nous retrouvons là les caractéristiques du sédiment loessique antérieur. L'unité 11 est issue du remaniement de la couverture loessique, avec dépôt des sables en pied de versant (faciès plus sableux rencontré en zone sud, cf. la base plus claire de l'unité 11 sur la photo 4). L'unité est attribuée au Dryas récent. Toutefois un diachronisme de l'unité est très probable : l'accumulation limoneuse a pu continuer dans les zones les plus basses au cours de l'Holocène, en particulier en liaison avec la mise en culture du versant et avec son occupation dense au cours de la Protohistoire (Prilaux et Favier, 2001).

Le petit talweg relique au pied du versant a connu une péripétie supplémentaire : encore sensible dans la topographie, il accueille une tourbe calcique galloromaine (déposée sous commande anthropique ?). Elle a protégé le sol sommital de l'unité 11 et son contenu archéologique.

\section{7 - UNE ZONE TÉMOIN DES VARIATIONS D'HUMIDITÉ AU TARDIGLACIAIRE}

\section{1 - UN ENREGISTREMENT ORIGINAL LIÉ AUX FLUCTUATIONS DE LA NAPPE}

La série sédimentaire du Marais de Dourges montre donc une accumulation de trois types de sédiments déposés dans une dépression fermée ou épisodiquement connectée avec le réseau hydrographique : limon tourbeux (unités 2, 5 et 8, présence d'une nappe phréatique affleurante), dépôt limoneux de crue (unité 3, 6, 7 inf.) et dépôt tuffacé dans un plan d'eau pérenne (unité 4 et, dans une moindre mesure, unité 7 sup.). L'absence d'incision lors des basculements climatiques (Pléniglaciaire/Bølling, Allerød/Holocène), la surreprésentation des phases chaudes et la variété des faciès rend ce bilan différent de celui des remplissages de chenaux étudiés dans les régions voisines (Antoine et al., 2002 ; Pastre et al., 2002 ; Huisink, 1997, 2000) ou même dans la vallée de la Deûle elle-même (Deschodt et al., 2004). La raison en est bien évidemment l'isolement du marais par rapport au réseau hydrographique. S'il n'en est pas totalement indépendant, il reste toutefois à l'abri des métamorphoses fluviales. Dans ces conditions, et en l'absence d'apports éoliens ou de versant, la sédimentation dans le marais est commandée par la fluctuation d'un plan d'eau alimenté principalement par la nappe. Le niveau de cette dernière est un bilan entre les précipitations et l'évapotranspiration, avec des cycles saisonniers (période végétative, répartition annuelle des précipitations et leur possible stockage sous forme de neige dans le cas de saisons contrastées). Fort de ce schéma théorique, nous pouvons essayer d'analyser les dépôts et hiatus observés dans le Marais de Dourges. L'analyse présentée infra est concordante avec la synthèse proposée pour les Pays-Bas par Bohncke et Vandenberghe (1991) (fig. 14), et à plus longue distance, avec les variations du niveau du lac de Montilier en Suisse (Magny et Richoz, 2000).

\section{2 - FROID ET SEC (DRYAS MOYEN, IACP)}

Les épisodes froids du Dryas moyen et de l'Intra Allerød Cold Period se caractérisent par une nappe phréatique basse et l'absence de dépôts. Une observation similaire (hiatus du Dryas moyen) a été faite sur une tourbière de basse terrasse dans la vallée de la Mark (Pays-Bas) (Bohncke et al., 1987 ; Vandenberghe et al., 1987). Les auteurs évoquent une cause morphologique (incision du lit mineur proche) pour expliquer un léger abaissement de la nappe. En l'absence d'une incision contemporaine dans la vallée de la Deûle (elle n'a pas été détectée dans le chenal passant à HouplinAncoisne, Deschodt et al., 2004), une cause climatique est à privilégier.

\section{3 - CHAUD ET PARFOIS SEC (FIN DE L'ALLERØD)}

Les interstades chauds ne sont pas pour autant toujours marqués par des conditions humides. Ainsi la fin de l'Allerød (11030 \pm 70 BP) paraît sec. La nappe est trop basse pour permettre la formation d'une tourbe. Un sol humifère (environ $2 \mathrm{~cm}$ épaisseur) recouvre l'ensemble de la zone. Il est postérieur à $11250 \pm 70 \mathrm{BP}$ et scelle le hiatus attribué à l'Intra Aller $\phi d$ Cold Period. De faciès uniforme quelque soit sa position topographique, il n'est pas lié à des conditions humides. Il est déjà précédé d'une tendance à la sécheresse sensible à travers le ralentissement du taux de sédimentation et le diachronisme du sommet de l'unité 8 (plus ancien en bordure du marais où la sédimentation s'arrête plus précocement, cf. datation du niveau Federmesser à 11680 BP). Le phénomène est à rapprocher de la nette tendance à la sécheresse observée dans les cortèges de malacofaunes des fonds de vallée du bassin parisien (Limondin-Lozouet, 2002). 


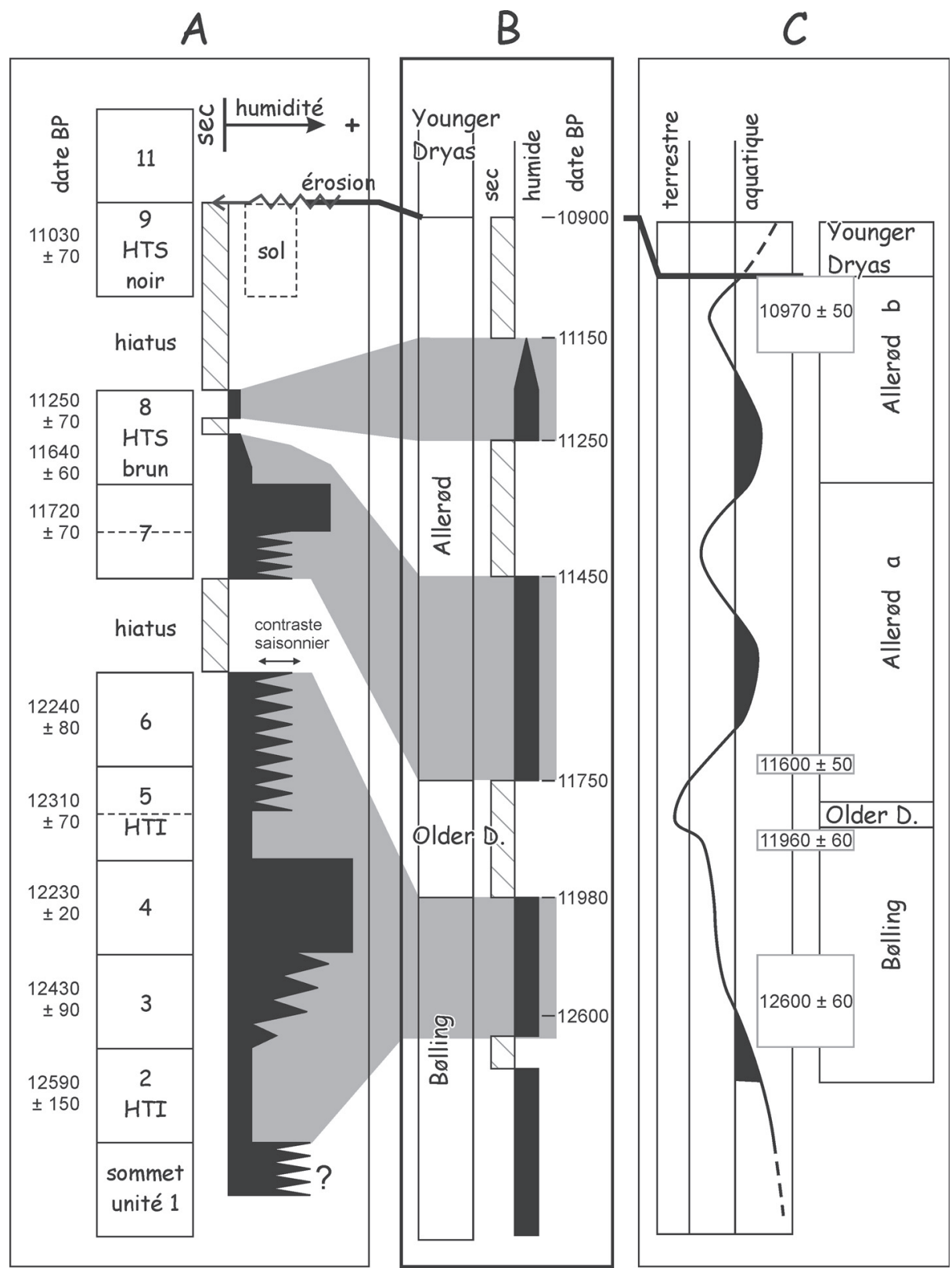

Fig. 14 : Evolution hydrologique du marais de Dourges et de comparaison avec les données des Pays-Bas.

A) marais de Dourges, B) synthèse pour le sud des Pays-Bas (d'après Bohncke et Vandenberghe, 1991), C) variation d'humidité (environnement aquatique ou terrestre) d'une tourbière de basse terrasse (Notsel, vallée de la Mark), d'après les données palynologiques et entomologiques (d'après Bohncke et al., 1987).

Fig. 14: Hydrological evolution of the Dourges marsh versus Netherlands data

A) Dourges marsh, B) Southern Netherlands synthesis (according to Bohncke and Vandenberghe, 1991), C) backswamp peat humidity variation (aquatic to terrestric environnement) on a low terrace (Notsel, Mark valley), from palynological and entomological data (according to Bohncke et al., 1987)

\section{4 - CHAUD ET TRÈS HUMIDE (BØLLING, REMONTÉE DE LA NAPPE)}

Il est probable que l'épisode lacustre, avec une nappe phréatique particulière haute au $\mathrm{B} \varnothing$ lling ait pu être favorisé (outre des précipitations abondantes) par l'inertie du développement de la couverture végétale (et donc de l'évapotranspiration) vis à vis de l'évolution climatique rapide (Limondin et al., 2002). Dans cette hypothèse, la succession des unités 2 et 3 serait liée à la remontée de la nappe au début du Bølling, les carbonates issus de l'environnement crayeux de la
Gohelle pouvait se concentrer et précipiter en abondance dans un plan d'eau peu profond et stagnant. Les dates obtenues dans cette partie de la coupe $(12590 \pm 150 \mathrm{BP}$ sur l'unité $2,12430 \pm 90$ et $12230 \pm 70 \mathrm{BP}$ sur les unités 3 et 4 ) indiquent d'ailleurs une contemporanéité avec le début des remplissages des chenaux en contexte strictement fluviatile. Dans le bassin parisien de nombreuses datations ont donné des résultats aux environs de 12400/12300 BP. La date la plus ancienne $(12540 \pm 110$ BP) a été obtenue à Houdancourt dans la vallée de l'Oise (Pastre et al., 2003). Notons sa proximité, non seulement avec la première formation 
tourbeuse de Dourges, mais aussi avec le début du comblement du chenal de la Deûle à Houplin-Ancoisne : $12560 \pm 100$ BP (Deschodt et al., 2004).

\section{5 - UN RÉGIME DE CRUES (FIN DU BØLLING, DÉBUT DE L'ALLERØD)}

Le marais de Dourges a été soumis à un dépôt de limon détritique. La présence de poissons mais l'absence de mollusques aquatiques (unités 3, 6, 7 inf.) impliquent des inondations brèves. Nous interprétons ces unités comme des dépôts d'inondations dues à des crues répétées mais courtes. Trois évolutions climatiques peuvent les expliquer :

(a) une augmentation des précipitations annuelles avec un débordement hivernal ou printanier des rivières suite à l'alimentation des cours d'eau par la nappe (ce schéma correspond au fonctionnement actuel du réseau hydrographique régional qui, sous climat océanique tempéré, est directement tributaire de la nappe phréatique et de sa recharge : Duchesne et al., 2000) ;

(b) une continentalisation du climat avec stockage hivernal des précipitations et fonte printanière brutale ;

(c) une récurrence accrue des précipitations orageuses de forte intensité (la région est en effet sensible à ce phénomène : Duchesne et al., 2000).

La transition observée entre les dépôts de crues et les maxima hydrologiques (passage de l'unité 3 vers l'unité 4 ou de l'unité 7 inférieure vers l'unité 7 sup.) est progressive, avec, surtout, une augmentation du taux de carbonate (fig. 9). Nous pensons donc qu'il s'agit d'un passage de crues saisonnières de courte durée vers des inondations plus longues, alimentées par une nappe phréatique haute. L'étalement des inondations dans le temps et vers la belle saison a favorisé la sédimentation tuffacée. Un plan d'eau permanent ou au moins persistant une grande partie de l'année (unité 4 et 7 sup.) en constitue le développement extrême.

La récurrence de crues constatées peut être mise en parallèle avec les inondations épisodiques observées sur une basse terrasse à Bosscherheide aux Pays-Bas. Comme à Dourges, elles débutent à la fin du Bølling (après $12100 \pm 70 \mathrm{BP}$ ), s'arrêtent au Dryas moyen et reprennent au début de l'Allerød (Bohncke et al., 1993). La vallée de la Selle (bassin de la Somme) semble être soumise au même régime hydrologique avec un exhaussement du fond de vallée, au cours de l'Allerød, témoignant de crues et d'une charge limoneuse dans les cours d'eau (Antoine et al., 2003). Toutefois, aucune phénomène équivalent n'a été observé sur la Deûle elle-même, plus en aval, où les alluvions sont confinées au lit mineur, encaissé entre les terrasses loessiques pléniglaciaires (Deschodt et al., 2004).

\section{CONCLUSION}

1) Entre les régions de la Gohelle et du Pévèle, l'extrémité orientale du bassin versant de la Deûle présente des dépressions fermées héritées du Pléniglaciaire weichsélien.

2) En l'absence de réseau hydrographique hiérarchisé, les dépressions ont vu se développer au cours du Tardiglaciaire une succession de formations palustres (avec turbification), de dépôts d'inondations (limon détritique), des plans d'eau persistants ou pérennes (précipitation de tuf). Cette sédimentation discontinue est commandée par les fluctuations de la nappe phréatique et donc par le bilan précipitation-évapotranspiration. L'étude de ce système morpho-sédimentaire original, à l'écart des grands systèmes fluviaux, est complémentaire des enregistrements de chenaux et contribue à la reconstitution paléo-climatique de la fin du Weichsélien.

3) Le maximum d'humidité est daté du Bølling. A l'opposé, le Dryas moyen et la fin de l'Allerød apparaissent secs. Un régime d'inondations se développe à la fin du Bølling et au début de l'Allerød. La péjoration froide du Dryas récent déstabilise les versants et provoque l'apport de colluvions. Elle marque une rupture avec le fonctionnement précédent.

4) Le marais de Dourges était particulièrement attractif pour la grande faune et les populations du Paléolithique. Le gisement de Dourges a permis de mettre en évidence la présence de l'Aurochs, particulièrement massif, et de l'Elan. Groupes de culture magdalénienne puis Federmesser se sont succédés, conformément à nos connaissances actuelles sur la recolonisation de la région à la fin des temps glaciaires. Ils ont abandonné un mobilier remarquable (harpon, pointe en os barbelée, sagaie).

5) Le marais de Dourges n'est pas un cas exceptionnel. A proximité, de nombreuses petites dépressions discrètes permettent de supposer la répétition du phénomène morpho-sédimentaire. La région offre dont un fort potentiel archéologique et paléontologique. De plus, l'existence de formes plus vigoureuses (CarvinEpinoy, fig. 1), voire encore en eau dans la plaine de la Scarpe voisine (Mer-de-Flines) laisser présager la présence d'enregistrements sédimentaires contemporains dilatés et détaillés.

\section{REMERCIEMENTS}

Le professeur A.V. Munaut n'a pu nous accompagner jusqu'à la conclusion de ce travail. Son départ laisse un grand vide, tant scientifique qu'humain.

Nous remercions P. Antoine et J. Sommé qui sont venus sur le terrain nous apporter leur aide et leurs conseils. Merci à J. Chung pour la relecture du résumé anglais. Nos meilleurs souvenirs à Tadich Eréo.

\section{BIBLIOGRAPHIE}

ADAM, W., 1960 - Mollusques terrestres et dulcicoles. Faune de Belgique, Mollusques, T.1, Bruxelles, 402 p.

ANTOINE, P., MUNAUT, A.V., LIMONDIN-LOZOUET, N., PONEL, P. et FAGNART, J.P., 2002 - Réponse des milieux de fond de vallée aux variations climatiques (Tardiglaciaire et début Holocène) d'après les données du bassin de la Selle (Nord de la 
France). Processus et bilans sédimentaires. In J.P. Bravard et M Magny (dir.), Les Fleuves ont une histoire. Paléoenvironnement des rivières et des lacs français depuis 15000 ans. Errance, 15-27.

AUGUSTE, P., 1995 - Cadres biostratigraphique et paléoécologique du peuplement humain dans la France septentrionale durant le Pléistocène. Apports de l'étude paléontologique des grands mammifères du gisement de Biache-Saint-Vaast (Pas-de-Calais). Thèse de Doctorat du Muséum National d'Histoire Naturelle de Paris, 5 vol., 724 p.

BERTRAN, P. et COUTARD, J.P. 2004 - Solifluxion. In P. Bertran (dir.), Dépôts de pentes continentaux. Dynamique et faciès. Quaternaire, Hors Série $\mathrm{n}^{\circ} 1,84-109$.

BOHNCKE, S., VANDENBERGHE, J., COOPE, R. et REILING, R. 1987 - Geomorphology and palaeoecology of the Mark valley (southern Netherlands): palaeoecology, palaeohydrology and climate during the Weichselian late Glacial. Boreas, 16, 69-85.

BOHNCKE, S. et VANDENBERGHE, J., 1991 - Palaeohydrological in the southern Netherlands during the last years. In L. Starkel, K.L. Gregory, J.B. Thornes (Eds), Temperate Palaeohydrology. Wiley and Sons Ltd, 253-281.

BOHNCKE, S., VANDENBERGHE, J. et HUIJZER, A.S., 1993 Periglacial environments during the Weichselian Late Glacial in the Maas valley, the Netherlands. Geologie en Mijnbouw, 72, 193 210

BOSTYN, F. et VALLIN, L., 1986 - L'outillage préhistorique en os de la région Nord-Pas-de-Calais. Inventaire et aspects techniques. Gallia Préhistoire, 29 (1), 193-215.

CHARLES, R., 1998 - Late Magdalenian Chronology and Faunal Exploitation in the North-Western Ardennes. BAR International Series 737, $246 \mathrm{p}$.

CORDY, J.-M., 1992 - Le contexte faunique du Magdalénien d'Europe du Nord-Ouest. In H. Laville, J.-Ph. Rigaud et B. Vandermeersch (eds.) «Le peuplement magdalénien. Paléogéographie physique et humaine », CTHS, Paris, 165-175.

DEGERBØL, M., FREDSKILD, B., 1970 - The Urus (Bos primige nius Bojanus) and Neolithic domesticated cattle (Bos taurus domesticus Linné) in Denmark, with a revision of Bos remains from kitchen middens. Det Kongelige Danske Videnskevernes Selskab, Biologiske Skrifter, 17 (1), 1-234.

DESCHODT, L. et BLANCQUAERT, G. 2000 - Plate-forme multimodale de Dourges, campagne de pré-sondages. Reconnaissance du contexte sédimentaire. 62274007AH, AFAN, SRA Nord-Pasde-Calais, 41 pages, rapport non publié.

DESCHODT, L., SALVADOR, P.G. et BOULEN, M, 2004 - Formations sédimentaires et évolution de la vallée de la Deûle depuis le Pléniglaciaire supérieur à Houplin-Ancoisne (Nord de la France). Quaternaire, 15 (3), 269-284.

DOIZE, R., 1952 - Quelques objets maglemôsiens trouvés en Belgique. Bulletin de la Société Royale Belge d'études géologiques et archéologiques, 15, 1-12.

DUCHESNE, C, LAGANIER, R. et ROUSSEL, I., 2000 - Vulnérabilité d'un hydrosystème fortement anthropisé : l'exemple du bassin minier Nord-Pas-de-Calais. In J.-P. Bravard (dir.) Les Régions Françaises face aux extrêmes hydrologiques. Gestion des excès et de la Pénurie. SEDES, 165-189.

EVANS, J.G., 1972 - Land snails in archaeology. Seminar Press, London and New York, $436 \mathrm{p}$.

FAGNART, J.P., 1997 - La fin des Temps glaciaires dans le nord de la France. Approches archéologiques et environnementale des occupations humaines du Tardiglaciaire. Mémoires de la Société Préhistorique Française, 24, 270 p.

HUISINK, M., 1997 - Late-glacial sedimentological and morphological changes in a lowland river in response to climatic change: the Maas, southern Netherlands. Journal of Quaternary Science, 12 (3), 209-223.

HUISINK M., 2000 - Changing river styles in response to Weichselian climate changes in the Vecht valley, eastern Netherlands. Sedimentary Geology, 133, 115-134.

JULIEN, M., 1982 - Les Harpons magdaléniens. XVII ${ }^{e}$ supplément à Gallia Préhistoire, éditions du CNRS, Paris.
KERNEY, M.P., CAMERON, R.A.D., JUNGBLUTH, J.H., 1983 Die Landschnecken Nord-und Mitteleuropas. Paul Parey, Hamburg und Berlin, $384 \mathrm{p}$.

LIMONDIN, N., 1995 - Late-glacial and Holocene Malacofaunas from Archaeological Sites in the Somme Valley (North France). Journal of Archaeological Science, 22, 683-698.

LIMONDIN-LOZOUET, N. et ANTOINE, P., 2001 - Palaeoenvironmental changes inferred from malacofaunas in the Lateglacial and Early Holocene fluvial sequence at Conty (Northern France). Boreas, 30, 148-164.

LIMONDIN-LOZOUET, N., 2002 - Impact des oscillations climatiques du Tardiglaciaire sur l'évolution des malacofaunes de fonds de vallée en Europe du Nord-Ouest. In H. Richard et A. Vignot (dir.) Equilibres et ruptures dans les écosystèmes durant les 20 derniers millénaires en Europe de l'Ouest. Presses Universitaires Franc-Comtoises, Annales Littéraires 730, Besançon, 45-51.

LIMONDIN-LOZOUET, N, BRIDAULT, A., LEROYER, C., PONel, P., ANTOINe, P., ChaUSSe, C., MUNAUT, A.V. et PASTRE, J.F., 2002 - Evolution des écosystèmes de fond de vallée en France septentrionale au cours du Tardiglaciaire : l'apport des indicateurs biologiques. In J.P. Bravard et M. Magny (dir.), Les Fleuves ont une histoire. Paléoenvironnement des rivières et des lacs français depuis 15000 ans. Errance, 2002, 45-62.

LORIN, Y., 2003 - Douvrin, sondages archéologiques, diagnostic 6215043601AH, INRAP, SRA Nord-Pas-de-Calais, rapport non publié.

MAGNY, M. et RICHOZ, I., 2000 - Lateglacial lake-level changes at Montilier-Strandweg, lake Morat, Switzerland, and their climatic significance. Quaternaire, 11 (2), 129-144.

MARCY, T., 2002 - Carvin, sondages archéologiques, INRAP, SRA Nord-Pas-de-Calais, rapport non publié.

PASTRE, J.F., LEROYER, C., LIMONDIN-LOZOUET, N., ORTH, P., CHAUSSE, C., FONTUGNe, M., GAUTHIER, A., KUNESCH, S, LE JEUNE, Y. et SAAD, M.C., 2002 - Variations paléoenvironnementales et paléohydrologiques durant les 15 derniers millénaires : les réponses morphosédimentaires des vallées du Bassin Parisien (France). In J.P. Bravard et M. Magny (dir.), Les Fleuves ont une histoire. Paléoenvironnement des rivières et des lacs français depuis 15000 ans. Errance, 15-27.

PASTRE, J.-F., LIMONDIN-LOZOUET, N., LEROYER, C., PONEL, P. et FONTUGNE, M., 2003 - River system evolution and environmental changes during the Lateglacial in the Paris Basin (France). Quaternary Science Reviews, 22, 2177-2188.

PRILAUX, G. et FAVIER, D., 2001 - Dourges « Le Marais de Dourges ». Occupations protohistoriques et gallo-romaines, 62274012 AH, AFAN, SRA Nord-Pas-de-Calais, 44 pages, rapport non publié.

STREET, M. et BAALES, M., 1999 - Pleistocene / Holocene changes in the Rhineland fauna in a northwest European context. In $\mathrm{N}$ Benecke (ed.) «The Holocene history of the European Vertebrate Fauna. Modern aspects of research ». Archäologie in Eurasien, 6 , $9-38$

TEHEUX, E. et DESCHODT, L., 2000 - Dourges, plate-forme multimodale. Rapport des évaluations paléolithiques à Hénin-Beaumont. Sites $n^{\circ} 62427025$ AH et 62427027 AH. AFAN, SRA NordPas-de-Calais 2000, 28 p., rapport non publié.

VANDENBERGHE, J., BOHNCKE, S., LAMMERS, W et ZILVERBERG, L, 1987 - Geomorphology and palaeoecology of the Mark valley (southern Netherlands): geomorphological valley developpement during the Weichselian and Holocene. Boreas, 16, 55-67.

VAN HUISSTEDEN, J., VAN DER VALK, L. et VANDENBERGHE, J., 1986 - Geomorphological evolution of a lowlands valley system during the Weichselian. Earth Surface Processes and Landforms, 11, 207-216.

WENIGER, G.C., 1992 - Function and form: an ethnoarchaeological analysis of barbed points from northern hunter-gatherer. Ethnoarchéologie : justification, problèmes, limites. XII Rencontres Internationales d'Archéologie et d'Histoire d'Antibes, éditions APDCA, Juan-les-Pins, 257-268. 